\title{
No need for more time: Intertemporal allocation decisions under time pressure
}

Florian Lindner, Julia Rose

Working Papers in Economics and Statistics 2016-24 


\section{University of Innsbruck \\ Working Papers in Economics and Statistics}

The series is jointly edited and published by

- Department of Banking and Finance

- Department of Economics

- Department of Public Finance

- Department of Statistics

Contact address of the editor:

Research platform "Empirical and Experimental Economics" University of Innsbruck

Universitaetsstrasse 15

A-6020 Innsbruck

Austria

Tel: $\quad+435125077171$

Fax: $\quad+435125072970$

E-mail: eeecon@uibk.ac.at

The most recent version of all working papers can be downloaded at http://eeecon.uibk.ac.at/wopec/

For a list of recent papers see the backpages of this paper. 


\title{
No need for more time: Intertemporal allocation decisions
}

\author{
under time pressure*
}

\author{
Florian Lindner ${ }^{\dagger} \quad$ Julia Rose ¿ $^{\ddagger}$
}

December 15, 2016

\begin{abstract}
Time preferences drive decisions in many economic contexts. For understanding the underlying decision process, it is key to identify what affects these preferences in different situations. To shed light on how people make intertemporal allocation choices, we analyze the stability of time preferences under time pressure. Conducting a laboratory study with 144 subjects using convex time budgets, we elicit time preferences with and without time pressure in a within-subject design. We find preferences to be stable across conditions for aggregate estimates of present-bias and utility function curvature. For standard discounting, we find subjects to be significantly less impatient under time pressure. All results hold across specifications and different sub-samples. Individual-level analyses confirm aggregate findings.
\end{abstract}

JEL-Classification: C91, D12, D81, D91.

Keywords: Time preferences, time pressure, decision-making, allocation decision, budget, experiment.

\footnotetext{
${ }^{*}$ We thank the guest editor of the special issue, Hannah Schildberg-Hörisch, two anonymous referees, Stefanie Gäbler, Christoph Huber, Jürgen Huber, Michael Kirchler, and Florentin Krämer for their helpful comments and suggestions. Financial support from the Center for Advanced Studies at the Ludwig-Maximilians-University of Munich is gratefully acknowledged.

${ }^{\dagger}$ Corresponding Author, florian.lindner@uibk.ac.at, +43 (0) 512507 73008, University of Innsbruck, Department of Banking and Finance, Universitätsstrasse 15, 6020 Innsbruck, Austria

${ }^{\ddagger}$ julia.rose@uibk.ac.at, +43 (0) 512507 73017, University of Innsbruck, Department of Banking and Finance, Universitätsstrasse 15, 6020 Innsbruck, Austria
} 


\section{Introduction}

Time preferences drive decisions in many economic contexts. To understand the underlying decision-making process, it is key to identify what affects these preferences in different situations. The focus of this paper is to shed further light on how people make intertemporal allocation choices by analyzing the stability of time preferences under severe time pressure in a laboratory setting.

Several studies find a significant influence of time pressure on the decision-making process in various experimental settings (Karagözoglu and Kocher, 2015; Kocher and Sutter, 2006; Rand et al., 2012; Sutter et al., 2003; Tinghög et al., 2013, 2016), while the main focus in the field of preferences under time pressure is on the analysis of choices under risk. (Kirchler et al., 2015; Kocher et al., 2013; Madan et al., 2015; Zur and Breznitz, 1981), for example, find increased risk aversion for losses under limited time for decision-making. As risk and time are intertwined, we are interested in the stability of time preferences when risk is controlled. ${ }^{1}$

Concerning the effects of time pressure on decision-making, psychological dual-systems models (Evans and Stanovich, 2013; Kahneman, 2003, 2011) offer a unified framework. While System I entails fast, automatic, and unconscious cognitive processes, System II operates deliberately and consciously. Since System II operations are relatively slow, they can be disrupted by extraneous influences such as time pressure (Finucane et al., 2000; Kahneman and Frederick, 2002). This framework is incorporated in various economic models, such as in O'Donoghue and Rabin (1999), Gul and Pesendorfer (2001), Loewenstein and O’Donoghue (2004), and Fudenberg and Levine (2006). Present-biased preferences are modeled as being generated by the interplay of two separate decision-making systems (affective and deliberate). The affective system values immediate gratification and discounts future periods. The deliberate system makes patient long-run plans. According to this theory, a variety of decision problems can be stated as games between a long-run patient self and a short-run impulsive self. Following these theoretical predictions, our results should point to increased present-bias and a higher degree of impatience under time pressure.

Using Convex Time Budgets (Andreoni et al., 2015; Andreoni and Sprenger, 2012a) in a within-subjects design, we compare aggregate and individual preferences under time pressure and

\footnotetext{
${ }^{1}$ (Andreoni and Sprenger, 2012b) suggest a clear distinction between risk and time preferences when manipulating risk in an intertemporal choice experiment. According to their findings, uncontrolled risk can generate apparently present-biased behavior.
} 
without time pressure for 144 subjects. In the time pressure condition, subjects are limited to five seconds to make a decision. In line with related studies, we do not find evidence for present-bias (Andreoni et al., 2015; Andreoni and Sprenger, 2012a). In contrast to theoretical predictions, however, we also do not find an increase in the degree of present-bias under time pressure. In addition, we find decisions to be significantly more patient under time pressure. With respect to utility function curvature, we find parameters to be stable across conditions. These findings are supported by individual estimates.

The remainder of the paper is organized as follows. After a brief review of the related literature in Section 2 and the presentation of the design of our experiment in Section 3, we outline the applied estimation strategies for the analysis in Section 4. Section 5 presents a descriptive overview of the results together with parameter estimates. Section 6 concludes.

\section{Related Literature}

The overview of the related literature covers two main aspects. First, we give a brief review of psychological findings on dual-systems theories along with recent economic studies concerned with the dual-systems approach. Second, we focus on the related experimental literature concerned with preferences under time pressure.

In the literature of dual-systems theory, a multitude of different models have evolved over the last decades. Adopting the most neutral terminology, studies distinguish between two systems, System I and System II. Even though theories differ with regard to their respective terminology and exact definitions, they agree on at least two major points (Evans, 2008): System I entails cognitive processes which are fast, automatic, and unconscious, whereas processes of System II are slow, deliberate, and conscious.

System I, as soon as judgment problems arise, quickly proposes intuitive answers. System II then monitors the quality of the respective proposals (Evans and Stanovich, 2013; Kahneman, 2003, 2011). However, since System II is operating relatively slowly, its operations can be disrupted by extraneous influences such as time pressure (Finucane et al., 2000). As a consequence, judgment heuristics are likely to yield simplistic assessments and are not always corrected by System II. In the process, biases are likely to disrupt decision-making. This is also supported by various theoretical models, where present-biased preferences are the result of an interplay of two separate systems. Whereas the affective system values immediate gratification, therefore 
discounting all future periods sharply, the deliberative system makes long-run plans with higher discount factors (Gul and Pesendorfer, 2001; Loewenstein and O'Donoghue, 2004; McClure et al., 2004; O'Donoghue and Rabin, 1999). Dual-self theories model many decision problems as games between long-run patient selves and short-run impulsive, completely myopic, selves. Further examples are Thaler and Shefrin (1981) and Fudenberg and Levine (2006), who propose models of impulse control and offer a unified explanation for a variety of empirical regularities.

A variety of experimental settings have been used to analyze intuitive versus deliberate decision-making in this context. Dreber et al. (2016) examine the role of self-control in the field of social preferences. Based on the model of Fudenberg and Levine (2006), they find that self-control requires some time for deliberation. Especially with regard to time pressure in an experimental environment, they find giving to increase with a decreasing time limit for decision-making as a result of lower self-control. ${ }^{2}$ In a different strand of literature, studies apply cognitive load or cognitive depletion to analyze characteristics of the decision-making process. Support for the predictions of dual-system models is provided by experimental studies which apply cognitive load while subjects make decisions in areas as diverse as asset markets (Kocher et al., 2016), social preferences (Schulz et al., 2014), and risk attitudes (Benjamin et al., 2013; Deck and Jahedi, 2015; Gerhardt et al., 2016). A number of studies analyze the influence of cognitive load on impatience. Experimental evidence in this context is mixed. While Hinson et al. (2003) as well as Benjamin et al. (2013) find greater discounting of delayed rewards under increased cognitive load, Deck and Jahedi (2015) do not find a higher degree of impatience under cognitive load when considering consumption good choices or choosing unhealthy snacks.

In the field of decision-making under time pressure, a growing body of literature analyzes the effects of limited time on experimental outcomes. The analysis of response times as well as explicitly constraining time frames for decision-making has gained in importance over the last few years; for a comprehensive overview of studies in this field see Spiliopoulos and Ortmann (2016).

One strand of literature in the field of time pressure is concerned with decision-making under limited time in bargaining. All studies find that efficiency decreases when subjects have limited time for making decisions. Sutter et al. (2003), for example, conduct an ultimatum game and

\footnotetext{
${ }^{2}$ In an earlier series of studies, Rand et al. (2012) analyze response times as well as explicitly conduct experiments under time pressure. Across all studies, they find shorter response times and increasing time pressure, respectively, being correlated with an increased level of cooperation and conclude cooperation to be intuitive. Even though Tinghög et al. (2013) find no such significant effect of time pressure on cooperation in a series of related experiments, Rand et al. (2013) confirm their previous findings with an aggregate analysis based on fifteen studies. Overall, findings suggest that increased cooperation under time pressure is a result of subjects intuitively deciding more cooperatively under limited time.
} 
find that, when provided with only a limited time to accept proposers' offers, subjects reject in about $60 \%$ of the cases when compared to only $20 \%$ without time pressure. In a recent study, Karagözoglu and Kocher (2015) conduct an unstructured experimental bargaining game with reference points. In line with the findings of Sutter et al. (2003), they find disagreement rates to be much higher under high time pressure than under low time pressure ( $31.4 \%$ vs. $4.5 \%)$. Cappelletti et al. (2011) analyze bargaining in an experimental ultimatum game under time pressure and cognitive load. Their results indicate that time pressure leads proposers to increase their offers in case their endowment is sufficiently high, whereas there are no significant differences in behavior when varying subjects' cognitive load.

A second strand of the literature is concerned with level- $k$ reasoning under time pressure. Kocher and Sutter (2006) conduct an experimental beauty-contest game and find slower convergence and lower payoffs under high time pressure compared to treatments under low time pressure. However, the findings also suggest that time-dependent payoffs under high time pressure lead to quicker decision-making, whereas the quality of decisions is not reduced. In a related study, Lindner and Sutter (2013) find that in an experimental 11-20 money request game subjects' play is close to, or even indistinguishable from, Nash equilibrium under time pressure.

Most closely related to our study are a variety of studies analyzing the influence of time pressure on individual risk preferences. A seminal paper in this field is the study of Zur and Breznitz (1981), who find that subjects' decisions are less risky under high as compared to medium and low time pressure. In a more recent study, Kocher et al. (2013) find that under time pressure, risk attitudes under gains are not affected, whereas an increased risk aversion for losses is observed. For mixed prospects, however, subjects become simultaneously more loss averse and more gain seeking depending on the task's framing. In general, they observe behavior to be more heuristic. Madan et al. (2015) obtain similar results; they state that under higher time pressure subjects choose risky options more often, independent of the outcome value. Additionally, they find time pressure to moderately increase risk seeking in decisions from experience. A related study by Kirchler et al. (2015) confirms these results: In a series of studies with more than 1,700 subjects in three countries, they find time pressure to increase risk aversion for gains and risk taking for losses. Hu et al. (2015) analyze the interaction of emotion and time pressure on decision-making in a risky environment. They find that both emotion and time pressure have a significant influence; positive emotions as well as high time pressure lead subjects to decide in a risk seeking way. 


\section{Experimental Design}

In a within-subject design, we elicit subjects' time preferences to compare behavior under time pressure with behavior in the absence of time pressure. The elicitation method used in the experimental task are Convex Time Budgets (CTB; Andreoni et al., 2015; Andreoni and Sprenger, 2012a). Subjects face 24 decisions in each condition, where each decision implies choosing one option out of a set of six different allocations of a given future value budget of $Y=€ 7.50$ between an earlier and later date in time. In addition to the corner solutions (receiving a smaller earlier payment $X$ at an earlier date vs. receiving $Y$ at a later point in time), subjects are provided with the option to choose four inner allocations. These allocations satisfy the condition $P x_{t}+x_{t+k}=Y$, where $x_{t}$ and $x_{t+k}$ are the chosen allocations at the earlier and later point in time; $P=\frac{Y}{X}=(1+r)$ captures the experimental gross interest rate. ${ }^{3}$ For each decision in the condition without time pressure, subjects had a time frame of 60 seconds per decision, which could be exceeded in case subjects needed more time for making their decisions. In the time pressure treatment, subjects had a time limit of five seconds per decision; afterwards the program automatically proceeded to the next decision screen. ${ }^{4}$

To be able to estimate all parameters of interest, decisions vary in time horizons and price ratios. The 24 decisions are divided into four different blocks with six decisions each, and blocks differ from each other with respect to time horizons. In the first block, subjects face allocations between today and 35 days from today, in the second block between today and 63 days from today. The third block involved allocations between in 35 and 70 days from today, while in block four decisions had to be made between in 35 and in 98 days from today. The comparison of blocks with identical delay length (block one vs. three, two vs. four) then allows to identify present-bias (Frederick et al., 2002; Laibson, 1997). Comparing blocks with different delay length (block one vs. two, three vs. four) allows us to characterize the degree of impatience and the estimation of a standard discounting parameter. Within each block, decisions vary in experimental gross interest rates, which permits identifying the curvature of the utility function. An overview of the experimental design together with price ratio and annual interest rates are displayed in Table 1.

\footnotetext{
${ }^{3}$ This method accounts for a major drawback of other standard elicitation methods as, for example, the Double Multiple Price List (DMPL) approach of Andersen et al. (2008). In their method, subjects are restricted to corner solutions while choosing between a smaller earlier payment and a larger later payment. Only in case of an actual underlying exponential utility function, this restriction is non-binding. If subjects have convex preferences, meaning that they preferred choosing interior solutions to the corner solutions available, the DMPL method restricts their behavior. In contrast to the DMPL method, where utility function curvature is identified via decisions in a separate risk elicitation task, in the CTB method curvature is identified via the degree of price sensitivity in intertemporal choice.

${ }^{4}$ Subjects earn $€ 0$ in case they are not able to decide within the given time frame under time pressure; for details see below and the Instruction in Appendix B.
} 
Table 1: Experimental Design

\begin{tabular}{|c|c|c|c|c|}
\hline $\begin{array}{c}\text { Days until } \\
\text { 1st payment }(t)\end{array}$ & $\begin{array}{l}\text { Delay } \\
(k)\end{array}$ & $t+k$ & $\begin{array}{c}\text { Price Ratio } \\
P\end{array}$ & Implied Annual Interest Rate \\
\hline 0 & 35 & 35 & $1.05,1.11,1.18,1.25,1.43,1.82$ & $65 \%, 164 \%, 312519 \%, 1301 \%, 4276 \%$ \\
\hline 0 & 63 & 63 & $1.00,1.05,1.18,1.33,1.67,2.22$ & $0 \%, 33 \%, 133 \%, 304 \%, 823 \%, 2093 \%$ \\
\hline 35 & 35 & 70 & $1.05,1.11,1.18,1.25,1.43,1.82$ & $65 \%, 164 \%, 312519 \%, 1301 \%, 4276 \%$ \\
\hline 35 & 63 & 98 & $1.00,1.05,1.18,1.33,1.67,2.22$ & $0 \%, 33 \%, 133 \%, 304 \%, 823 \%, 2093 \%$ \\
\hline
\end{tabular}

Notes: For each of the 24 decisions in the CTB, earlier dates and delay lengths are given together with the respective price ratios. Effective yearly rates are calculated with quarterly compounding.

Seven sessions were conducted in the blinded with a total of 144 participants between June, 11 and June 18, 2014. Subjects were recruited with the help of ORSEE (Greiner, 2015) out of a standard subject pool without any restrictions. The experiment was computerized in z-Tree (Fischbacher, 2007). While the order of blocks was fixed, the order of the respective decisions within each block was randomized across subjects and treatments. Each decision was presented on a single screen. Figure 1 shows an example for a subject's decision screen. The elicitation of time preferences was conducted as the second part of an experiment with five separate parts in total, lasting for about one and a half hours of which the two CTB tasks took about 20 minutes. Printed instructions were given to subjects before each part and were read aloud by the experimenter. Detailed instructions can be found in Appendix B. At the end of the task, one of the 48 CTB decisions was randomly drawn for payment. Subjects were told that their chosen option in this decision situation would be paid out and that they would be only informed about the randomly chosen decision situation at the end of the experiment. In case a subject failed to decide on one of the presented options in a specific decision situation and the respective option was randomly chosen for payment at the end of the experiment, subjects earned $€ 0$. These procedures were explained in detail in the instructions and were maintained for incentive compatibility. All payments were transferred to the subjects' bank accounts at the respective dates of the decision randomly chosen for payment to account for equal transaction costs with regard to present and future payoffs. Additionally, since we are interested in the isolated effect of time pressure on time preferences we eliminate the potentially higher risk of future payments by transferring both the earlier and later payments to a subject's bank account, even in case the earlier date is today. ${ }^{5}$

\footnotetext{
${ }^{5}$ The experimental payment dates thus implied that the transfer of payments was initiated on this day, which holds transaction costs constant across treatments and dates and also between treatments, since one of the 48 decisions in total is randomly chosen for payment.
} 


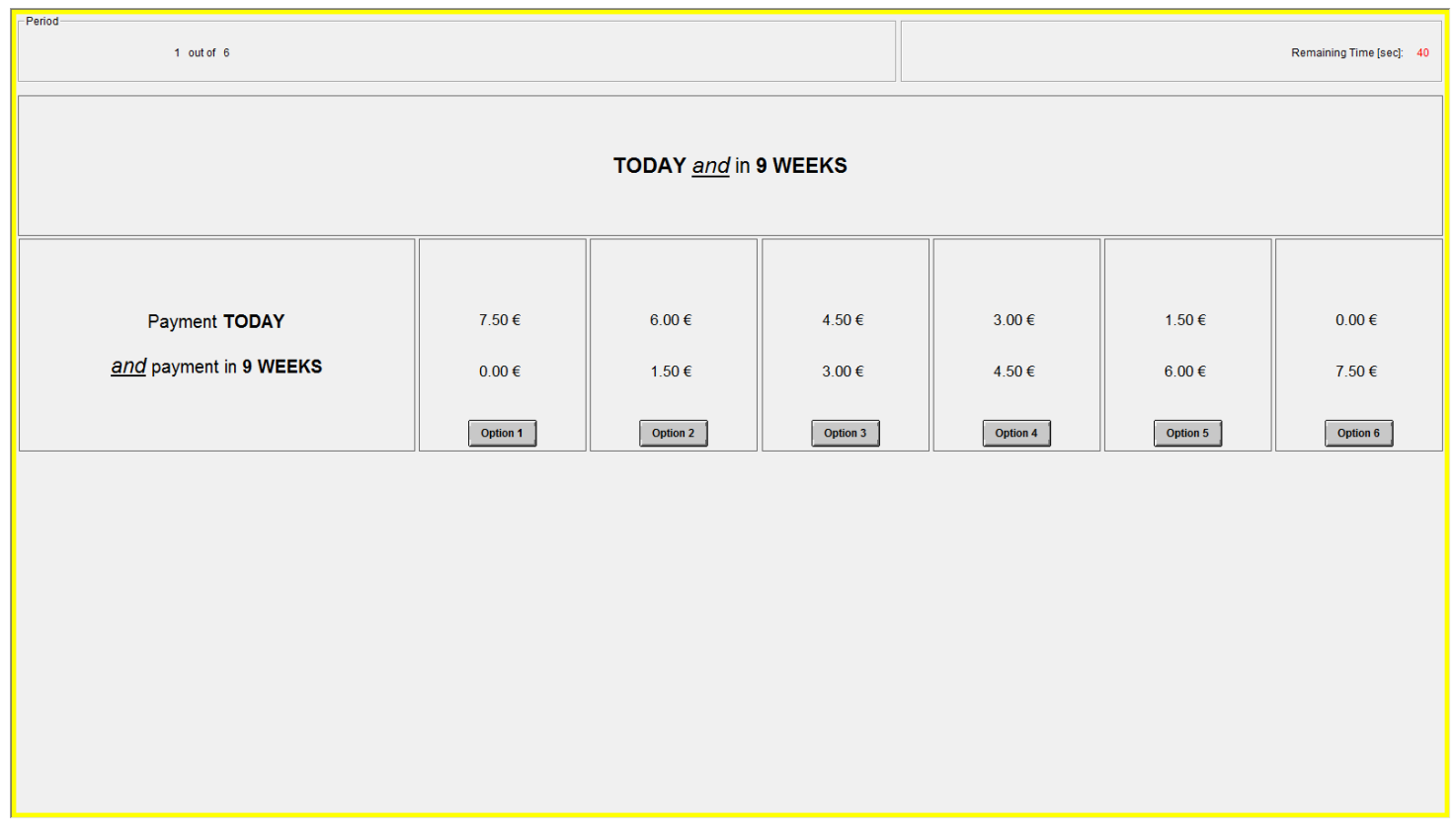

Figure 1: Example of a subject's decision screen in the CTB task (block two)

\section{Parameter Estimation Strategies}

The specific experimental design allows us to estimate all parameters of interest with non-linear least squares (NLS) and interval-censored Tobit (ICT) methods to be able to compare aggregate as well as individual estimates across treatments in addition to descriptive results.

For the subsequent analysis, subjects' per-period preferences are assumed to be stationary and time-independent with constant relative risk aversion (CRRA): $u\left(x_{t}\right)=x_{t}^{\alpha}$. Discounting is modeled to be of a quasi-hyperbolic form to be able to capture dynamic inconsistencies in subjects' discounting behavior by including a parameter for present-bias (Laibson, 1997; O'Donoghue and Rabin, 1999). Preferences are then defined in the following way:

$$
U\left(x_{t}, x_{t+k}\right)=x_{t}^{\alpha}+\beta^{t_{0}} \delta^{k} x_{t+k}^{\alpha},
$$

where $x_{t}$ and $x_{t}+k$ are the chosen allocations of payment at the earlier and later date, respectively. $\alpha$ captures the curvature of the utility function, $\delta$ is the measure for standard discounting, and $\beta$ captures subjects' present-bias and is therefore a measure for time-inconsistency. $t_{0}$ is a time indicator with $t_{0}=1$ if the present is considered and 0 otherwise. $k$ denotes the delay length of later payments in days. The utility function nests linear utility $(\alpha=1)$ as well as standard exponential discounting $(\beta=1)$. 
Utility is maximized subject to the future value budget constraint:

$$
(1+r) x_{t}+x_{t+k}=Y
$$

where $(1+r)=P$ is the experimental gross interest rate or price ratio.

The standard Euler equation is obtained by maximizing subjects' utility (1) subject to the future value budget constraint (2):

$$
M R S=\frac{x_{t}^{\alpha-1}}{\beta^{t_{0}} \delta^{k} x_{t+k}^{\alpha-1}}=P
$$

where the marginal rate of substitution $(M R S)$ equals the price ratio $(P)$.

The NLS regression equation is based on the demand function:

$$
x_{t}=\frac{Y\left(\beta^{t_{0}} \delta^{k} P\right)^{\left(\frac{1}{\alpha-1}\right)}}{1+P\left(\beta^{t_{0}} \delta^{k} P\right)^{\left(\frac{1}{\alpha-1}\right)}}
$$

where $Y$ denotes the future value budget, which in our case equals $€ 7.50$. In our experimental design, $P$ and $Y$ are given; $x_{t}$ is the subject's decision, and $\alpha, \beta$, and $\delta$ are to be estimated. Note that Equation 4 is only defined for $\alpha \neq 1$. However, this can be considered as a minor problem for our subsequent analysis due to the fact that experimental data provides vast evidence for the majority of subjects being risk averse for high and close to risk neutral, but still risk averse, for lower stakes (Holt and Laury, 2002, 2005). Additionally, even though estimating a non-linear equation does not account for the interval nature of the data, previous papers have shown that estimating an ICT regression model performed as a robustness check for the NLS regression produces equivalent results (Andreoni et al., 2015; Lührmann et al., 2015). Moreover, the estimate for the curvature parameter $\alpha$ cannot be separately identified from the stochastic disturbance term $\tau$ in an ICT regression. Thus, we perform ICT regressions as robustness checks of NLS techniques, while the latter is the focus of our parametric analysis.

The basis for the ICT regression is a simplified form of the log-linearized marginal rate of substitution (3) with indices $i$ for individual and $j$ for budget number:

$$
y_{i j}^{*}=\ln \left(\frac{x_{t(i j)}^{*}}{x_{t+k(i j)}^{*}}\right)=\gamma_{1} t_{0 i j}+\gamma_{2} k_{i j}+\gamma_{3} \ln \left(P_{i j}\right)+e_{i j} .
$$


As part of the parameter estimation, five cut points have to be defined. With regard to simplification, we define the cut points to be the upper bounds of the respective intervals. Additionally, to allow for stochastic choice and to be able to account for inconsistencies in subjects' decisions, a stochastic disturbance term $\tau$ as a weight on the error term $e$ is included, which is assumed to be distributed according to a logistic distribution function and i.i.d. across choices and individuals. As explained above, the estimate for utility function curvature, $\alpha$, cannot be estimated precisely due to a lack of identification since $\alpha=\frac{\tau}{\gamma_{3}}+1$. However, the estimates for present-bias $\beta$ and standard discounting $\delta$ are not affected since they are identified from the ratio of $\gamma$ coefficients $\left(\beta=\exp \left(\frac{\gamma_{1}}{\gamma_{3}}\right), \delta=\exp \left(\frac{\gamma_{2}}{\gamma_{3}}\right)\right)$. A more detailed description of the ICT estimation is given in Appendix A.1.

\section{Analysis}

In the main analysis, we present results obtained from the full sample of 144 subjects. Additionally, we provide robustness checks by dividing the full sample into two sub-samples to separately analyze subjects who are most affected by time pressure, i.e. those subjects who did not manage to respond on time in at least one of the decisions in the condition under time pressure. In our data, 53 subjects had at least one missing input. We compare this sub-sample to the set of subjects with no missing input (91 subjects). We find that preferences are stable across all three specifications with respect to the curvature of the utility function $\alpha$ and present-bias $\beta$, while subjects are less impatient under time pressure. Additionally, our results show that choices are not more random under time pressure than in the condition without time pressure when comparing the distributions of inconsistent choices across conditions ( $p=0.2020$, Kolmogorov-Smirnov test). An overview of the structure of missing input and inconsistencies is given in Figure 4 in Appendix A.2. ${ }^{6}$ Additionally, we provide aggregate results for two additional sub-samples in Appendix A.3 as robustness checks: first, we analyze 62 subjects with no missing inputs and no inconsistent choices; second, we examine 82 subjects with at least one missing input and / or at least one inconsistent choice in one of the conditions. We find that our results are robust also to these specifications.

\footnotetext{
${ }^{6}$ Inconsistent choices in the CTB task are decision blocks with multiple switching. Multiple switching is defined as allocating a lower fraction of the budget to the earlier date at a higher price ratio compared to a lower price ratio and can be interpreted as a form of non-monotonic demand. Since both NLS and ICT regressions can account for minor inconsistencies, we decided to include all subjects with inconsistent choices in our analysis, since there are only very few outliers with more than two inconsistencies.
} 


\subsection{Descriptive Analysis}

For a descriptive analysis of present-bias with and without time pressure, Figure 2 compares the mean allocated share of the budget to the earlier date in decisions without front end delay (nFED) and front end delay (FED) separated into short (35 days) and long delay lengths (63 days). We provide $p$-values obtained by Wilcoxon signed-rank tests for differences between conditions (see Table 2). We present aggregate descriptive results for all 144 subjects in our main analysis. Separate descriptive analyses for the sub-sample of 91 subjects with no missing input as well as for the sub-sample of 53 subjects with at least one missing input can be found in Appendix A.2. ${ }^{7}$ For nFED decisions, the earliest possible date at which subjects can choose to receive a fraction of their payment is today, whereas for FED decisions, the earliest possible date of payment is in 35 days from the day of the experiment.

To start with the most basic comparison, we find that the average chosen option under time pressure over all 24 decisions is not significantly different from the average chosen option without time pressure $(p=0.2236){ }^{8}$ In a next step, we compare the degree of present-bias across conditions. An indication of time-inconsistent choices is a significantly higher allocated fraction of the budget to the earlier date when the respective date is in the present. Considering the condition without time pressure, for short delay mean fractions of the budget allocated to the earlier date are marginally higher for nFED decisions compared to FED decisions at all price ratios. However, differences in mean allocations to the earlier date are significant at the 5\%-level only at price ratios of $1.11,1.25$, and 1.43 , respectively. For all other price ratios, differences are not significant $(p>10 \%)$.

For long delay, mean fractions of the budget allocated to the earlier date are even marginally higher for FED decisions at all price ratios except for $P=2.22$, indicating slight future-bias. However, differences are not significant for all six price ratios $(p>10 \%)$, except of $P=2.22$ $(p=0.0198)$. Taken together, we do not find evidence for present-bias without time pressure; a result consistent with Andreoni and Sprenger (2012a), who also observe a lack of evidence for present-bias using the same elicitation method. ${ }^{9}$

\footnotetext{
${ }^{7}$ Note that missing inputs are only possible in the condition with time pressure.

${ }^{8}$ To check if the manipulation of time pressure was strong enough, we present histograms of both conditions in the Appendix A.2, Figure 5. The mean decision time without time pressure was 6.01 and 1.17 seconds under time pressure $(p=0.0000$, Wilcoxon signed-rank test).

${ }^{9}$ Additionally, since we transfer both the earlier and the later payments to a subject's bank account (even in case the earlier payment is today), we hold the potential risk of not receiving the experimental payments constant across dates. This procedure additionally ensures the equality of transaction costs across dates.
} 
Table 2: Descriptive Comparison of Present-Bias: Mean Allocated Share to the earlier Date - No Front End Delay vs. Front End Delay

\begin{tabular}{|c|c|c|c|c|c|c|c|c|c|c|c|c|c|}
\hline & & \multicolumn{6}{|c|}{ No Time Pressure } & \multicolumn{6}{|c|}{ Time Pressure } \\
\hline \multirow{4}{*}{ Short Delay } & $P$ & 1.05 & 1.11 & 1.18 & 1.25 & 1.43 & 1.82 & 1.05 & 1.11 & 1.18 & 1.25 & 1.43 & 1.82 \\
\hline & $n F E D$ & 0.3681 & 0.2389 & 0.1847 & 0.1611 & 0.0861 & 0.0611 & 0.3504 & 0.1878 & 0.1659 & 0.1914 & 0.1362 & 0.0843 \\
\hline & $F E D$ & 0.3417 & 0.2000 & 0.1778 & 0.1139 & 0.0681 & 0.0458 & 0.3248 & 0.1775 & 0.1239 & 0.1447 & 0.0610 & 0.0479 \\
\hline & $p$-value & 0.4030 & 0.0463 & 0.1892 & 0.0151 & 0.0491 & 0.2480 & 0.2015 & 0.0235 & 0.0059 & 0.0874 & 0.0002 & 0.1260 \\
\hline \multirow{4}{*}{ Long Delay } & $P$ & 1.00 & 1.05 & 1.18 & 1.33 & 1.67 & 2.22 & 1.00 & 1.05 & 1.18 & 1.33 & 1.67 & 2.22 \\
\hline & $n F E D$ & 0.8153 & 0.4083 & 0.1847 & 0.1319 & 0.0625 & 0.0653 & 0.7304 & 0.3453 & 0.1930 & 0.0892 & 0.0791 & 0.0559 \\
\hline & $F E D$ & 0.8472 & 0.4264 & 0.2167 & 0.1514 & 0.0792 & 0.0472 & 0.7690 & 0.3497 & 0.1873 & 0.1083 & 0.0771 & 0.0577 \\
\hline & $p$-value & 0.2400 & 0.6321 & 0.3287 & 0.4113 & 0.9551 & 0.0198 & 0.3590 & 0.7988 & 0.8807 & 0.1165 & 0.2749 & 0.7565 \\
\hline
\end{tabular}

Note: All values correspond to the descriptive analysis in Figure 2.P denotes the experimental gross interest rate of the respective decision, short delay corresponds to a
delay of 35 days, whereas long delay corresponds to 63 days. $p$-values indicate the significance of differences across no front-end delay (nFED) and front-end delay (FED) decisions (Wilcoxon singed-rank tests). 
Results are similar for decisions under time pressure. We observe marginally higher mean fractions of the budget allocated to the earlier date for nFED decisions compared to FED decisions for short delay. Differences are significant for price ratios of $1.11,1.18,1.25$, and $1.43(p=0.0235$, $p=0.0059, p=0.0847$, and 0.0002 , respectively). For all other differences, $p>10 \%$. Due to the inclusion of subjects with inconsistent decisions in the present analysis, we observe that the curves for mean allocated shares to the present are not monotonically decreasing in price ratios for short delay in the condition with time pressure. Mean allocated shares to the earlier date are increasing between price ratios of $P=1.18$ and 1.25 , and decreasing for all subsequent price ratios. However, increases are not significant for $\mathrm{nFED}$ decisions $(p=0.5615)$ and only marginally significant for FED decisions $(p=0.0689)$. For that reason we decide not to drop any outliers with a high number of inconsistent decisions from the subsequent analysis. With long delay, mean fractions of the budget allocated to the earlier date are higher for FED decisions at price ratios of $P=1.00$, $1.05,1.33$, and 2.22; pointing to a slight future-bias. However, differences are insignificant for all price ratios $(p>10 \%)$. Overall, we do not find evidence for present-bias across both conditions.

To analyze the significance of the difference in the degree of present-bias between conditions, we present a graphical analysis of differences in differences of mean shares between conditions. For both conditions, we compute differences between the mean fraction of the budget allocated to the earlier date for nFED and FED decisions for short as well as long delay. Aggregate results are displayed in Figure 3. We find that differences in differences are not significant for short delay except for $P=1.43(p=0.0037)$ and long delay except for $P=2.22(p=0.0841)$. We conclude that the degree of present-bias cannot be rejected to be similar across conditions.

Embedding our findings in the context of dual-self theory, we do not find evidence for a difference between intuitive and deliberate decision-making with respect to present-bias. Even though subjects are put under severe time pressure with only 5 seconds of time to choose one out of six possible options in each decision situation, we do not find significant differences in present-bias between the two conditions. Overall, we do not find evidence of time pressure disrupting deliberative operations, which would result in observing a higher degree of present-bias according to theoretical dual-self models (Fudenberg and Levine, 2006; Gul and Pesendorfer, 2001; Loewenstein and O'Donoghue, 2004; O'Donoghue and Rabin, 1999). 
No Time Pressure
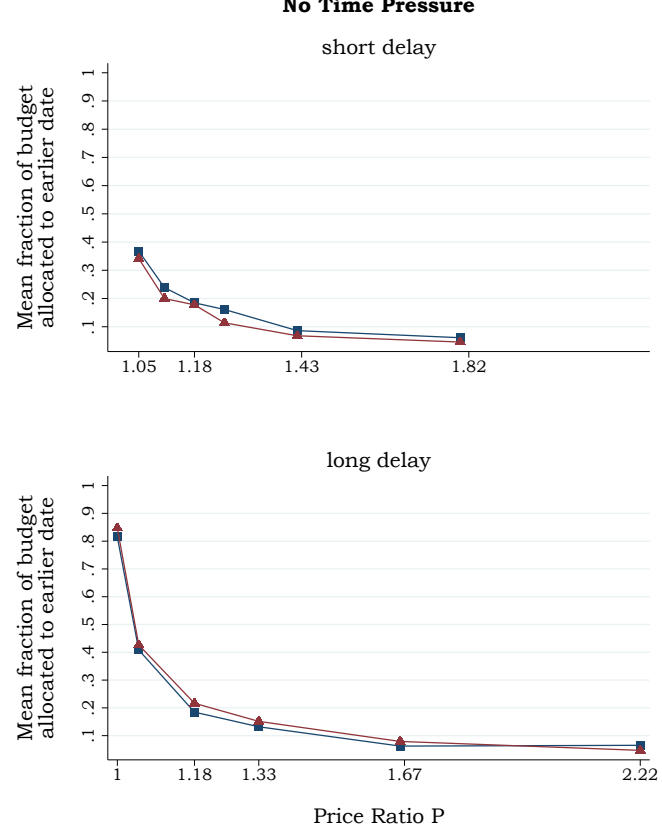

Time Pressure

short delay

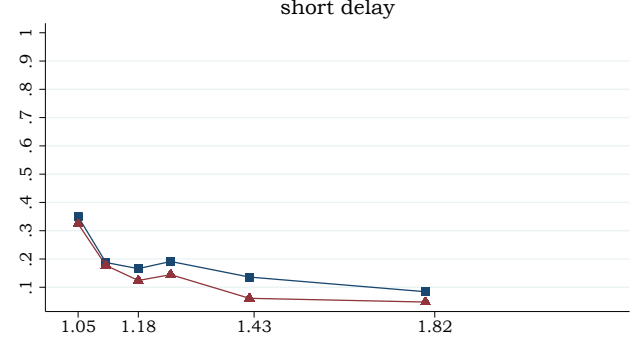

long delay

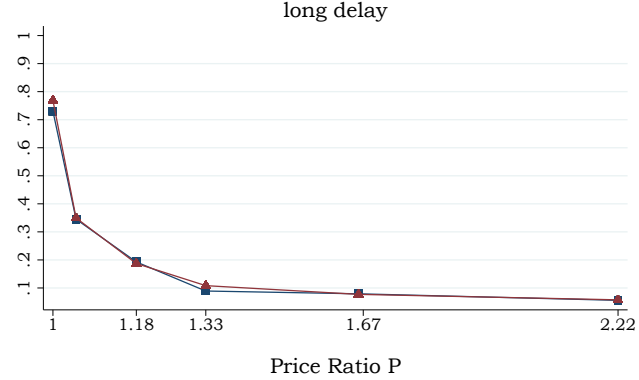

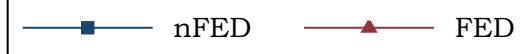

Figure 2: Comparison of present-bias with and without time pressure

Note: The top row of the figure compares the mean allocated share of the budget to the earlier date between nFED and FED decisions for a time delay of 35 days, whereas the bottom row shows differences for a delay length of 63 days.
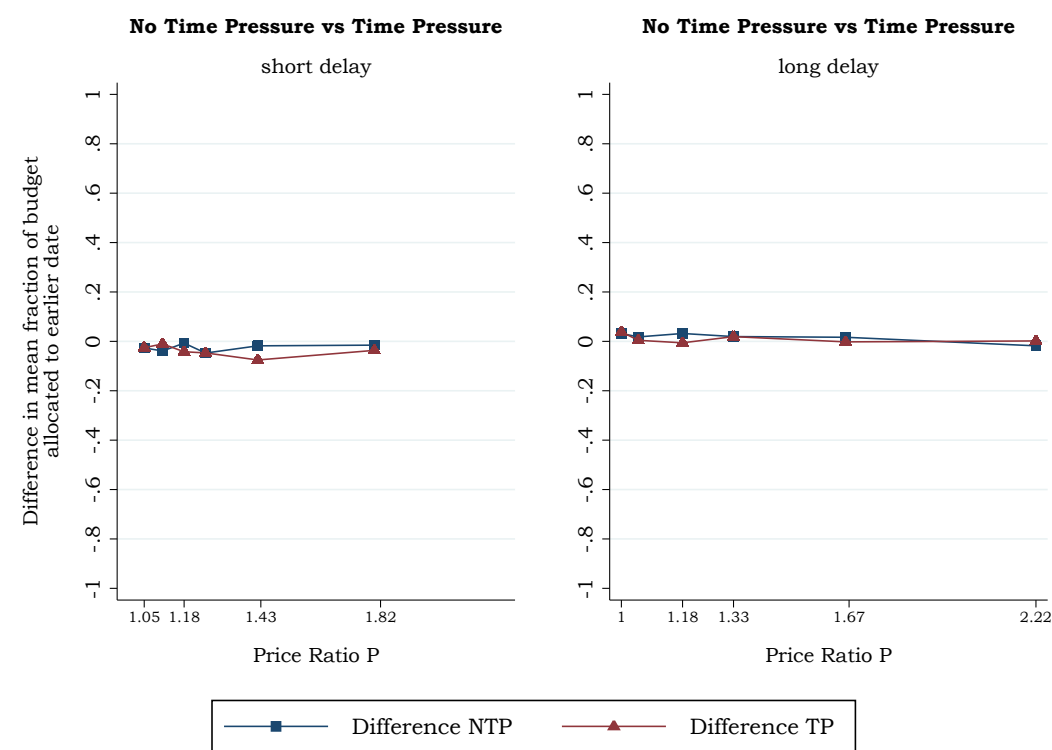

Note: The left graph depicts differences between nFED and FED decisions for short delay for NTP and TP conditions, respectively. Similarly, the right graph depicts differences between nFED and FED decisions for long delay for NTP and TP conditions.

Figure 3: Differences in present-bias between the condition under time pressure and without time pressure 


\subsection{Parameter Estimation}

To quantify and confirm the directional findings of the descriptive analysis, we estimate all relevant parameters of interest using NLS techniques. Additionally, we analyze individual differences in more detail. ICT regressions for both conditions are performed as robustness checks where we allow for stochastic choices. The ICT estimation procedure follows the approach of Lührmann et al. (2015); more detailed information is provided in Appendix A.1. Since the curvature of the utility function cannot be identified separately from the stochastic disturbance term $\tau$ and the procedure is less transparent, we focus our interpretation on the NLS estimation results and provide ICT estimates as robustness checks. In the following, we analyze results for the full sample of 144 subjects as well as the subset of 93 subjects with no missing input under time pressure, and the subset of 53 subjects with at least one missing input (i.e. those subjects who are most affected by time pressure).

Table 3 displays aggregate results of the parameter estimation for time pressure as well as no time pressure and all sub-samples. In addition to standard discounting $\delta$, we compute the aggregate annual discount rate $\left(\right.$ rate $\left.=\left(\frac{1}{\delta}\right)^{365}-1\right)$. rate captures the aggregate degree of impatience: the smaller $\delta$, the larger rate and the more impatient subjects are on the aggregate level. Reporting rate in addition to $\delta$ also illustrates that even marginal differences in $\delta$ translate into substantial differences in the aggregate annual discount rate.

Effects go in the same direction for all specifications. In the subsequent analysis, we present $p$-values obtained by Wald tests. For the full sample of 144 subjects, results indicate time-consistency across conditions ( $\beta=1.0026$ without time pressure, $\beta=1.0014$ under time pressure). Exponential discounting cannot be rejected across conditions with $p=0.7988$ (no time pressure) and $p=$ 0.9987 (time pressure). The equality of parameters across conditions cannot be rejected with $p=0.8391$. The results confirm the descriptive findings and indicate stability of time-consistency under increased time pressure. 
Table 3: Aggregate Parameter Estimates

\begin{tabular}{|c|c|c|c|c|c|c|c|c|c|c|c|c|}
\hline & \multicolumn{4}{|c|}{ All 144 Subjects } & \multicolumn{4}{|c|}{91 Subjects (0 missings) } & \multicolumn{4}{|c|}{53 Subjects ( $>0$ missings) } \\
\hline & $\begin{array}{l}\text { No Time } \\
\text { (NLS) }\end{array}$ & $\begin{array}{l}\text { Pressure } \\
\text { (ICT) }\end{array}$ & $\begin{array}{l}\text { Time } \\
(\mathrm{NLS})\end{array}$ & $\begin{array}{r}\text { Pressure } \\
\text { (ICT) }\end{array}$ & $\begin{array}{l}\text { No Time } \\
\text { (NLS) }\end{array}$ & $\begin{array}{l}\text { Pressure } \\
\quad(\mathrm{ICT})\end{array}$ & $\underset{(\mathrm{NLS})}{\text { Time }}$ & $\begin{array}{l}\text { Pressure } \\
\qquad(\mathrm{ICT})\end{array}$ & $\begin{array}{l}\text { No Time } \\
\text { (NLS) }\end{array}$ & $\begin{array}{l}\text { Pressure } \\
\quad(\mathrm{ICT})\end{array}$ & $\begin{array}{l}\text { Time } \mathbf{F} \\
(\mathrm{NLS})\end{array}$ & $\begin{array}{l}\text { ressure } \\
\text { (ICT) }\end{array}$ \\
\hline$\alpha$ & $\begin{array}{c}0.9417^{* * *} \\
(0.0055)\end{array}$ & $\begin{array}{c}0.9886^{* * *} \\
-0.0025\end{array}$ & $\begin{array}{c}0.9414^{* * *} \\
(0.0056)\end{array}$ & $\begin{array}{c}0.9842^{* * *} \\
(0.0037)\end{array}$ & $\begin{array}{c}0.9502^{* * *} \\
(0.0060)\end{array}$ & $\begin{array}{c}0.9907 * * * \\
(0.0026)\end{array}$ & $\begin{array}{c}0.9558^{* * *} \\
(0.0056)\end{array}$ & $\begin{array}{c}0.9923 * * * \\
(0.0028)\end{array}$ & $\begin{array}{c}0.9295^{* * *} \\
(0.0111)\end{array}$ & $\begin{array}{c}0.9853^{* * *} \\
(0.0052)\end{array}$ & $\begin{array}{c}0.9072^{* * *} \\
(0.0135)\end{array}$ & $\begin{array}{c}0.9676^{* * *} \\
(0.0099)\end{array}$ \\
\hline$\beta$ & $\begin{array}{c}1.0026 \\
(0.0047)\end{array}$ & $\begin{array}{c}1.0115 \\
(0.0110)\end{array}$ & $\begin{array}{c}1.0014 \\
(0.0056)\end{array}$ & $\begin{array}{c}0.9998 \\
(0.0164)\end{array}$ & $\begin{array}{c}1.0000 \\
(0.0051)\end{array}$ & $\begin{array}{c}1.0137 \\
(0.0132)\end{array}$ & $\begin{array}{c}0.9993 \\
(0.0055)\end{array}$ & $\begin{array}{c}1.0080 \\
(0.0173)\end{array}$ & $\begin{array}{c}1.0066 \\
(0.0093)\end{array}$ & $\begin{array}{c}1.0072 \\
(0.0196)\end{array}$ & $\begin{array}{c}1.0024 \\
(0.0139)\end{array}$ & $\begin{array}{c}0.9814 \\
(0.0326)\end{array}$ \\
\hline$\delta$ & $\begin{array}{c}0.9991^{* * *} \\
(0.0001)\end{array}$ & $\begin{array}{c}0.9990^{* * *} \\
(0.0002)\end{array}$ & $\begin{array}{c}0.9994^{* * *} \\
(0.0001)\end{array}$ & $\begin{array}{c}1.0000 \\
(0.0004)\end{array}$ & $\begin{array}{c}0.9993^{* * *} \\
(0.0001)\end{array}$ & $\begin{array}{c}0.9993^{* *} \\
(0.0003)\end{array}$ & $\begin{array}{c}0.9994^{* * *} \\
(0.0001)\end{array}$ & $\begin{array}{c}1.0000 \\
(0.0004)\end{array}$ & $\begin{array}{c}0.9987^{* * *} \\
(0.0002)\end{array}$ & $\begin{array}{c}0.9984^{* * *} \\
(0.0005)\end{array}$ & $\begin{array}{c}0.9993^{* *} \\
(0.0003)\end{array}$ & $\begin{array}{c}0.9996 \\
(0.0008)\end{array}$ \\
\hline$\tau$ & - & $\begin{array}{c}13.8950 \\
(2.3580)\end{array}$ & - & $\begin{array}{c}12.099 \\
(2.0934)\end{array}$ & - & $\begin{array}{l}15.5859 \\
(3.6547)\end{array}$ & - & $\begin{array}{c}20.5955 \\
(6.1208)\end{array}$ & - & $\begin{array}{l}11.8393 \\
(2.9081)\end{array}$ & - & $\begin{array}{c}7.2272 \\
(1.4513)\end{array}$ \\
\hline rate & $38.68 \%$ & $41.76 \%$ & $25.63 \%$ & $1.07 \%$ & $30.33 \%$ & $26.23 \%$ & $23.17 \%$ & $-1.76 \%$ & $57.05 \%$ & $80.64 \%$ & $28.11 \%$ & $19.02 \%$ \\
\hline $\begin{array}{l}\text { \# Observations } \\
\text { \# Clusters }\end{array}$ & $\begin{array}{c}3,456 \\
144\end{array}$ & $\begin{array}{c}3,456 \\
144\end{array}$ & $\begin{array}{c}3,367 \\
144\end{array}$ & $\begin{array}{c}3,367 \\
144\end{array}$ & $\begin{array}{c}2,184 \\
91\end{array}$ & $\begin{array}{c}2,184 \\
91\end{array}$ & $\begin{array}{c}2,184 \\
91\end{array}$ & $\begin{array}{c}2,184 \\
91\end{array}$ & $\begin{array}{c}1,272 \\
53\end{array}$ & $\begin{array}{c}1,272 \\
53\end{array}$ & $\begin{array}{c}1,183 \\
53\end{array}$ & $\begin{array}{c}1,183 \\
53\end{array}$ \\
\hline
\end{tabular}

Note: Parameters are estimated via NLS and ICT regressions; where ICT indicates results obtained by specifying Fechner errors. ***, **, and * indicate significance on the $1 \%$, $5 \%$, and $10 \%$ level, respectively, for testing the hypotheses of linear utility $(\alpha=1)$, exponential discounting $(\beta=1)$, and no standard discounting $(\delta=1)$ on an aggregate level (Wald tests). For ICT it is not as $(1 / \delta)^{365}-1$. Standard errors are given in parentheses and clustered on the individual level. Parameters are nonlinear combinations of regression coefficients and respective standard errors are computed via the Delta method. ICT regressions are estimated using the Broyden-Fletcher-Goldfarb-Shanno (BFGS) optimization algorithm. 
Comparing differences in the curvature of the utility function across conditions $(\alpha=0.9417$ without time pressure, $\alpha=0.9414$ under time pressure), linear utility can be rejected at the $1 \%$-level ( $p=0.0000$ for both conditions). As for the estimates for present-bias, $\alpha$ does not differ significantly between conditions $(p=0.3154)$. In contrast, we find significant differences in discounting between conditions $(p=0.0244)$ with $\delta=0.9991$ (no time pressure) and $\delta=0.9994$ (time pressure). Even though the difference in the estimates is only marginal, differences in the aggregate annual discount rate illustrate that the significance is not only a merely statistical finding. With rate $=38.68 \%$ without time pressure compared to rate $=25.63 \%$ under time pressure, we find subjects to be more patient under time pressure.

Overall, we find time preferences to be stable with respect to the curvature of the utility function and present-bias. In line with descriptive findings, we do not find evidence for an increase in time-inconsistency, which contrasts the predictions of theoretical dual-self models (Fudenberg and Levine, 2006; Gul and Pesendorfer, 2001; Loewenstein and O'Donoghue, 2004; O'Donoghue and Rabin, 1999). However, what we find is that subjects are more patient under time pressure with a difference of 13.05 percentage points in the aggregate annual discount rate, which is also at odds with theoretical predictions.

Estimates go in the same direction across regression methods. ICT estimates quantitatively confirm the findings obtained by NLS regressions. Whereas $\alpha$ and $\beta$ are not significantly different across conditions ( $p=0.2347$ and $p=0.4746$, respectively), $\delta$ increases in the time pressure condition compared to no time pressure and is significant on the 1\%-level for ICT estimates ( $p=0.0083)$. With a difference of 40.69 percentage points between conditions, the computed aggregate annual discount rate confirms NLS results: subjects are significantly more patient under time pressure.

Comparing the full sample of 144 subjects to the sub-sample without any missing inputs (91 subjects) as well as the sub-sample with at least one missing input (53 subjects), we find similar results. For all sub-samples, we can reject linear utility at the $1 \%$-level, whereas exponential discounting cannot be rejected $(p>0.4820)$ across conditions and specifications. Furthermore, parameters for utility function curvature and present-bias are not significantly different between conditions with $p>0.1035$ and $p>0.7644$, respectively. For the aggregate standard discounting parameter, differences between conditions are not significant for the subset of 91 subjects with no missing inputs ( $p=0.1897$ ), and only marginally significant on the $10 \%$-level for the 53 subjects 

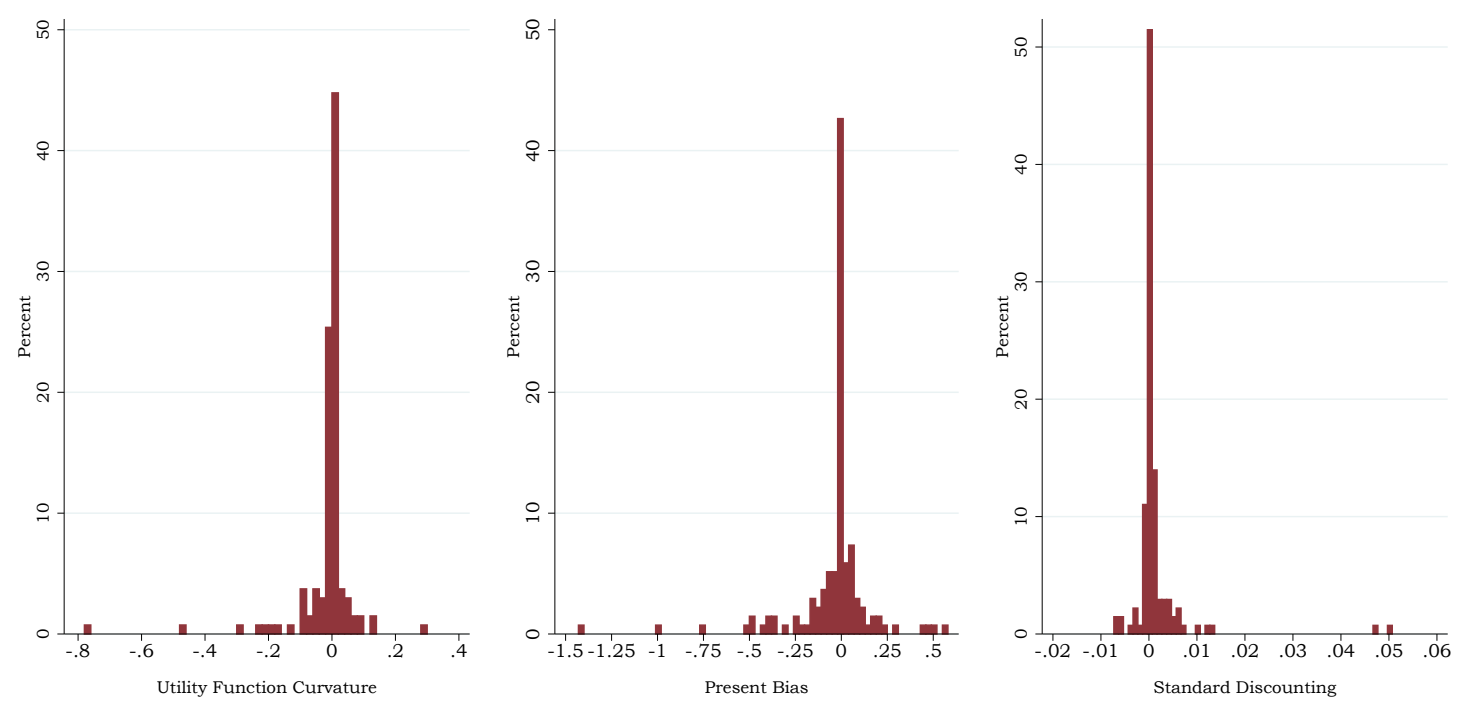

Figure 4: Distributions of individual differences of estimates between conditions

with at least one missing input $(p=0.0726)$. Overall, as indicated by the aggregate annual discount rate, results confirm findings for the full sample; subjects are more patient under time pressure. ${ }^{10}$

To analyze stability across conditions on the individual level and to quantify directional findings, we compute the differences between individual parameters without time pressure and under time pressure. $^{11}$ Using Wald tests, we check whether these differences are significant and stability can be rejected; stability is rejected for all p-values below the $10 \%$-level. Figure 4 illustrates the distributions of the individual differences of estimated parameters between conditions. ${ }^{12}$

For all three parameters of interest, we find that for the majority of subjects differences in individual estimates between conditions are marginal. ${ }^{13}$ While for $\alpha$ and $\beta$ distributions are close to symmetric around zero, we find a higher fraction of positive differences for standard discounting $\delta$. This confirms aggregate findings: with a lower $\delta$ under time pressure, the individual annual discount rate derived from the standard discounting parameter is lower under time pressure for the majority of subjects. For 36 subjects $(25.35 \%)$, all parameters are identical across both conditions.

\footnotetext{
${ }^{10}$ We provide the analysis separated into those subjects without missing input and inconsistent choices and those with at least one missing input and / or one inconsistency in Appendix A.3.

${ }^{11}$ For this analysis, we were able to estimate individual parameters for 142 out of 144 subjects. All individual parameters are estimated via NLS.

${ }^{12}$ In addition, we provide a detailed table (see Appendix A.4, Table 7) indicating whether the estimated parameter on the individual level in the time pressure condition was below or above the parameter in the condition without time pressure, and whether the difference was significant and stability is rejected.

${ }^{13}$ Note that these marginal differences translate into substantial differences in the annual discount rate.
} 
With respect to the curvature of the utility function, for 78 subjects $(80.28 \%)$ differences are not significant; stability cannot be rejected across conditions. For present-bias $\beta$, results are similar. In 84 cases $(84.51 \%)$, parameters are not significantly different from the no time pressure condition. Considering standard discounting $\delta$, for a fraction of $66.90 \%$ of all subjects stability cannot be rejected. In total, for 61 subjects $(42.96 \%)$ we find a lower degree of impatience under time pressure, which supports previous aggregate findings, while we find a higher degree of impatience under time pressure for only $31.69 \%$ of all subjects.

Taken as a whole, findings confirm descriptive and aggregate estimation results. With respect to the curvature of the utility function and present-bias, the majority of subjects can be categorized as stable. Concerning standard discounting, we find subjects to be less impatient under time pressure.

\section{Conclusion}

In many economic contexts, time preferences are important drivers for individual decisions. Characterizing and identifying the influencing factors of these preferences in different situations is at the core of understanding the decision-making process of intertemporal allocations. By analyzing the stability of time preferences under severe time pressure, we take the next step in characterizing individual time preferences in different contexts.

Our findings indicate that the degree of utility function curvature as well as present-bias is stable across conditions. With respect to standard discounting, we find subjects being significantly less impatient under time pressure. These results contradict standard psychological and theoretical economic models in two ways. First, while psychological and behavioral models in dual-systems theory propose present-biased preferences to evolve from the interplay of an affective and a deliberate system, where the latter can be disrupted in its operations by time pressure (Kahneman and Frederick, 2002), we do not find evidence for such a distinction in our analysis. Second, models predict a higher degree of impatience under time pressure, whereas we find the opposite: subjects are significantly more patient under time pressure. Our aggregate results hold for different sub-samples and across estimation methods; the individual analysis further confirms our findings. 


\section{References}

Andersen, S., Harrison, G. W., Lau, M. I., and Rutström, E. E. (2008). Eliciting risk and time preferences. Econometrica, 76(3):583-618.

Andreoni, J., Kuhn, M. A., and Sprenger, C. (2015). Measuring time preferences: A comparison of experimental methods. Journal of Economic Behavior \& Organization, 116:451-464.

Andreoni, J. and Sprenger, C. (2012a). Estimating time preferences from convex budgets. American Economic Review, 102(7):3333-3356.

Andreoni, J. and Sprenger, C. (2012b). Risk preferences are not time preferences. American Economic Review, 102(7):3357-3376.

Benjamin, D. J., Brown, S. A., and Shapiro, J. M. (2013). Who is 'behavioral'? cognitive ability and anomalous preferences. Journal of the European Economic Association, 11(6):1231-1255.

Cappelletti, D., Güth, W., and Ploner, M. (2011). Being of two minds: Ultimatum offers under cognitive constraints. Journal of Economic Psychology, 32(6):940-950.

Deck, C. and Jahedi, S. (2015). The effect of cognitive load on economic decision making: A survey and new experiments. European Economic Review, 78:97-119.

Dreber, A., Fudenberg, D., Levine, D. K., and Rand, D. G. (February 17, 2016). Self-control, social preferences and the effect of delayed payments. Available at SSRN: http://ssrn.com/abstract $=2477454$.

Evans, J. S. B. (2008). Dual-processing accounts of reasoning, judgment, and social cognition. Annual Review of Psychology, 59:255-278.

Evans, J. S. B. and Stanovich, K. E. (2013). Dual-process theories of higher cognition advancing the debate. Perspectives on Psychological Science, 8(3):223-241.

Finucane, M. L., Alhakami, A., Slovic, P., and Johnson, S. M. (2000). The affect heuristic in judgments of risks and benefits. Journal of Behavioral Decision Making, 13(1):1-17.

Fischbacher, U. (2007). z-Tree: Zurich toolbox for ready-made economic experiments. Experimental Economics, 10(2):171-178.

Frederick, S., Loewenstein, G., and O'Donoghue, T. (2002). Time discounting and time preference: A critical review. Journal of Economic Literature, 40(2):351-401. 
Fudenberg, D. and Levine, D. K. (2006). A dual-self model of impulse control. American Economic Review, 96(5):1449-1476.

Gerhardt, H., Biele, G. P., Uhlig, H., and Heekeren, H. (March, 2016). Cognitive load increases risk aversion. SFB 649 Discussion Paper 2016-011.

Greiner, B. (2015). Subject pool recruitment procedures: Organizing experiments with ORSEE. Journal of the Economic Science Association, 1(1):114-125.

Gul, F. and Pesendorfer, W. (2001). Temptation and self-control. Econometrica, 69(6):1403-1435.

Hinson, J. M., Jameson, T. L., and Whitney, P. (2003). Impulsive decision making and working memory. Journal of Experimental Psychology: Learning, Memory, and Cognition, 29(2):298-306.

Holt, C. A. and Laury, S. K. (2002). Risk aversion and incentive effects. American Economic Review, 92(5):1644-1655.

Holt, C. A. and Laury, S. K. (2005). Risk aversion and incentive effects: New data without order effects. American Economic Review, 95(3):902-904.

Hu, Y., Wang, D., Pang, K., Xu, G., and Guo, J. (2015). The effect of emotion and time pressure on risk decision-making. Journal of Risk Research, 18(5):637-650.

Kahneman, D. (2003). A perspective on judgment and choice: Mapping bounded rationality. American Psychologist, 58(9):697-720.

Kahneman, D. (2011). Thinking, fast and slow. Farrak, Straus and Giroux, New York.

Kahneman, D. and Frederick, S. (2002). Representativeness revisited: Attribute substitution in intuitive judgment. Cambridge University Press.

Karagözoglu, E. and Kocher, M. G. (2015). Bargaining under time pressure. Munich Discussion Paper No. 2015-21.

Kirchler, M., Andersson, D., Bonn, C., Johanesson, M., Sørensen, E. Ø., Stefan, M., Tinghög, G., and Västfjäll, D. (2015). The effect of fast and slow decisions on financial risk taking. Working Paper.

Kocher, M. G., Lucks, K. E., and Schindler, D. (2016). Unleashing animal spirits - Self-control and overpricing in experimental asset markets. CESifo Working Paper Series No. 5812.

Kocher, M. G., Pahlke, J., and Trautmann, S. T. (2013). Tempus fugit: Time pressure in risky decisions. Management Science, 59(10):2380-2391. 
Kocher, M. G. and Sutter, M. (2006). Time is money - Time pressure, incentives, and the quality of decision-making. Journal of Economic Behavior 63 Organization, 61(3):375-392.

Laibson, D. (1997). Golden eggs and hyperbolic discounting. Quarterly Journal of Economics, 112(2):443-477.

Lindner, F. and Sutter, M. (2013). Level- $k$ reasoning and time pressure in the 11-20 money request game. Economics Letters, 120(3):542-545.

Loewenstein, G. and O'Donoghue, T. (2004). Animal spirits: Affective and deliberative processes in economic behavior. Available at SSRN: https://ssrn.com/abstract=539843.

Loomes, G., Moffatt, P. G., and Sugden, R. (2002). A microeconometric test of alternative stochastic theories of risky choice. Journal of Risk and Uncertainty, 24(2):103-130.

Lührmann, M., Serra-Garcia, M., and Winter, J. K. (2015). The impact of financial education on adolescents' intertemporal choices. CESifo Working Paper Series No. 4925.

Madan, C. R., Spetch, M. L., and Ludvig, E. A. (2015). Rapid makes risky: Time pressure increases risk seeking in decisions from experience. Journal of Cognitive Psychology, 27(8):921-928.

McClure, S. M., Laibson, D. I., Loewenstein, G., and Cohen, J. D. (2004). Separate neural systems value immediate and delayed monetary rewards. Science, 306(5695):503-507.

O’Donoghue, T. and Rabin, M. (1999). Doing it now or later. American Economic Review, 89(1):103-124.

Rand, D. G., Greene, J. D., and Nowak, M. A. (2012). Spontaneous giving and calculated greed. Nature, 489(7416):427-430.

Rand, D. G., Greene, J. D., and Nowak, M. A. (2013). Rand et al. reply. Nature, 498(7452):E2-E3.

Schulz, J. F., Fischbacher, U., Thöni, C., and Utikal, V. (2014). Affect and fairness: Dictator games under cognitive load. Journal of Economic Psychology, 41:77-87.

Spiliopoulos, L. and Ortmann, A. (2016). The BCD of response time analysis in experimental economics. Available at SSRN: http://ssrn.com/abstract $=2401325$.

Sutter, M., Kocher, M., and Strauß, S. (2003). Bargaining under time pressure in an experimental ultimatum game. Economics Letters, 81(3):341-347.

Thaler, R. H. and Shefrin, H. M. (1981). An economic theory of self-control. Journal of Political Economy, 89(2):392-406. 
Tinghög, G., Andersson, D., Bonn, C., Böttiger, H., Josephson, C., Lundgren, G., Västfjäll, D., Kirchler, M., and Johannesson, M. (2013). Intuition and cooperation reconsidered. Nature, 498(7452):E1-E2.

Tinghög, G., Andersson, D., Bonn, C., Johannesson, M., Kirchler, M., Koppel, L., and Västfjäll, D. (2016). Intuition and moral decision-making - The effect of time pressure and cognitive load on moral judgment and altruistic behavior. PLOS ONE, 11(10):e0164012.

Zur, H. B. and Breznitz, S. J. (1981). The effect of time pressure on risky choice behavior. Acta Psychologica, 47(2):89-104. 


\section{Appendix}

\section{A Econometric Specification and Robustness Checks}

\section{A.1 ICT Regression}

Due to the interval nature of our data, we perform interval censored Tobit (ICT) regressions as robustness checks for NLS regression methods following the approach of Lührmann et al. (2015), where observed choices are interpreted as ordinal indicators of preference and optimality is assumed to hold only for the underlying, unobserved optimal choices from fully convex budgets. Furthermore, the observed choices are related to the optimality conditions in a probabilistic way, the model allows for stochastic choice. Fechner or "white noise" errors capture the assumption that individuals maximize utility while having a set of alternative preference relations. When deciding in a specific decision problem, the individual acts on one of these preference relations, where the specific one is selected randomly (Loomes et al., 2002). Our model therefore includes a stochastic disturbance term $\tau$ as a weight on the error term $e$, which is assumed to be distributed according to a logistic distribution function and i.i.d. across choices and individuals.

The ICT regression is based on the simplified OLS equation with the latent variable $y_{i j}^{*}$ to be estimated. $i$ and $j$ are indexing variables for individuals and budgets, respectively:

$$
y_{i j}^{*}=\ln \left(\frac{x_{t(i j)}^{*}}{x_{t+k(i j)}^{*}}\right)=\gamma_{1} t_{0 i j}+\gamma_{2} k_{i j}+\gamma_{3} \ln \left(P_{i j}\right)+e_{i j}
$$

where $t_{0}$ is the indicator variable for the present, $k$ is the delay length and $P$ is the experimental gross interest rate; $\gamma_{1}=\frac{\ln (\beta)}{\alpha-1}, \gamma_{2}=\frac{\ln (\delta)}{\alpha-1}, \gamma_{3}=\frac{1}{\alpha-1} . e_{i j}$ is supposed to be normally distributed $\left(e_{i j} \sim \mathcal{N}\left(0, \sigma^{2}\right)\right)$.

For each decision and individual, the six choices $(c=1,2, \ldots, 6)$ can be categorized in the following way according to their preference for earlier payment:

$$
c= \begin{cases}1, & \text { if } y^{*}>K^{1}, \\ 2, & \text { if } K^{1}>y^{*}>K^{2} \\ \vdots & \\ 6, & \text { if } K^{5}>y^{*}\end{cases}
$$

where $K^{1}, \ldots, K^{5}$ are five cut points which capture both observed and unobserved parts of 
preferences. However, these cut points are not to be interpreted as indifference points between adjacent choices. With the above distribution of the error term $e_{i j}$, the probabilities of the individual's choices for each decision are:

$$
\begin{aligned}
\operatorname{Pr}\left(c_{i j}=n\right) & =\operatorname{Pr}\left(K_{j}^{n-1}<y^{*}<K_{j}^{n}\right) \\
& =\operatorname{Pr}\left(K_{j}^{n-1}-\left(\gamma_{1} t_{0 i j}+\gamma_{2} k_{i j}+\gamma_{3} \ln \left(P_{i j}\right)\right)<e_{i j}<K_{j}^{n}-\left(\gamma_{1} t_{0 i j}+\gamma_{2} k_{i j}+\gamma_{3} \ln \left(P_{i j}\right)\right)\right) \\
& =\Lambda\left(\frac{1}{\tau}\left(K_{j}^{n-1}-\left(\gamma_{1} t_{0 i j}+\gamma_{2} k_{i j}+\gamma_{3} \ln \left(P_{i j}\right)\right)\right)\right)-\Lambda\left(\frac{1}{\tau}\left(K_{j}^{n}-\left(\gamma_{1} t_{0 i j}+\gamma_{2} k_{i j}+\gamma_{3} \ln \left(P_{i j}\right)\right)\right)\right)
\end{aligned}
$$

where $\Lambda(t)=\left(1+e^{-1}\right)$ is the CDF of the logistic distribution; the derivation for the corner solution probabilities is analogous. We define the cut points to be the upper side of each interval per assumption.

As already outlined in Section 4, the parameters $\gamma_{1}, \gamma_{2}, \gamma_{3}$ in Equation 6 are only defined up to $\tau$, the stochastic disturbance term. Therefore, the estimate for utility function curvature, $\alpha$, cannot be estimated precisely due to a lack of identification since $\alpha=\frac{\tau}{\gamma_{3}}+1$. However, the estimates for present-bias $\beta$ and standard discounting $\delta$ are not affected since they are identified from the ratio of $\gamma$ coefficients $\left(\beta=\exp \left(\frac{\gamma_{1}}{\gamma_{3}}\right), \delta=\exp \left(\frac{\gamma_{2}}{\gamma_{3}}\right)\right)$. 


\section{A.2 Descriptive Analysis}
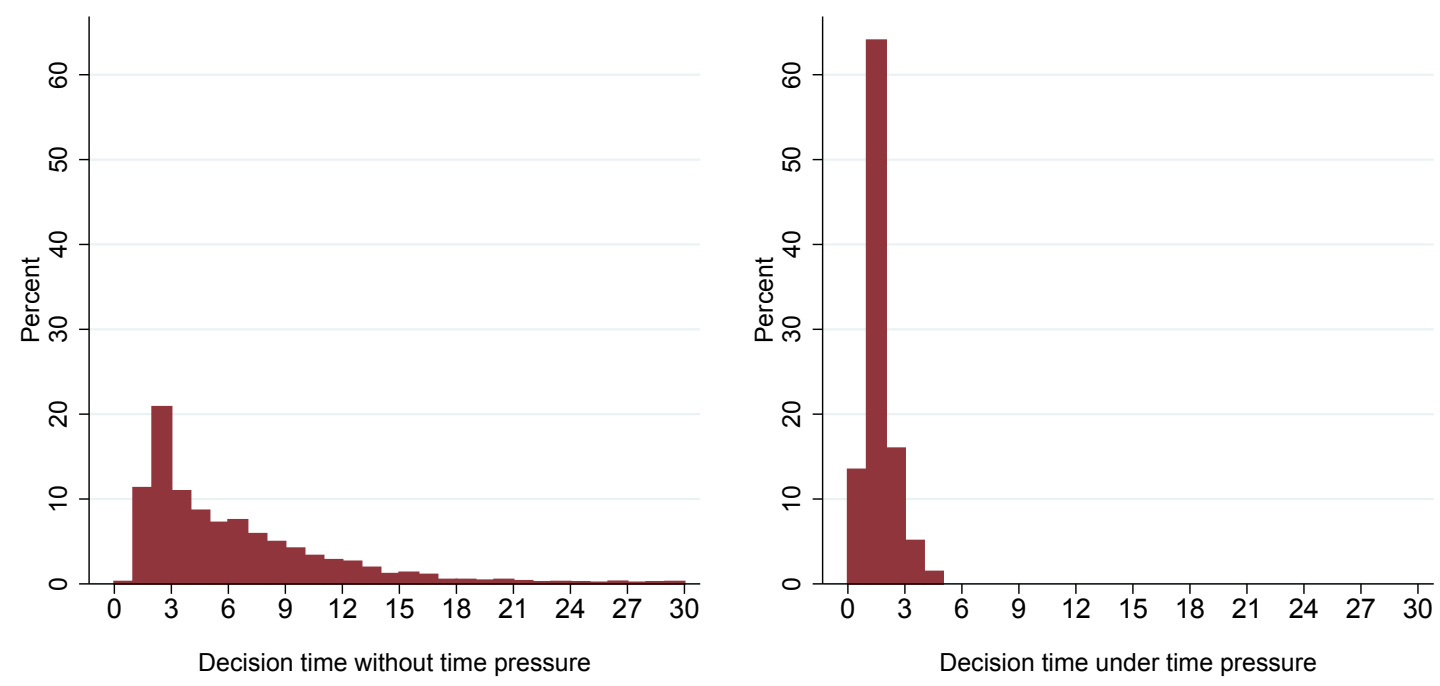

Note: The left (right) graph shows the distribution of the decision time without (under) time pressure.

Figure 5: Distribution of the decision time under time pressure and without time pressure

Table 4 displays the structure of missing inputs in the condition with time pressure and the structure of inconsistent decisions across conditions. The sum of inconsistencies represents the total number of inconsistent decisions in each condition (without time pressure, NTP; under time pressure, TP). We find that only the minority of people display more than two missing inputs. The structure of inconsistencies across conditions is not significantly different $(p=0.2020$, Kolmogorov-Smirnov test).

Table 4: Structure of missing input and inconsistencies

\begin{tabular}{cccccc}
$\begin{array}{c}\text { \# of missing } \\
\text { inputs }\end{array}$ & Frequency & $\begin{array}{c}\text { \# of } \\
\text { Inconsistencies NTP }\end{array}$ & Frequency & $\begin{array}{c}\text { \# of } \\
\text { Inconsistencies TP }\end{array}$ & Frequency \\
\hline 0 & 91 & 0 & 106 & 0 & 98 \\
1 & 32 & 1 & 18 & 1 & 20 \\
2 & 10 & 2 & 10 & 2 & 6 \\
3 & 8 & 3 & 4 & 3 & 11 \\
4 & 2 & 4 & 2 & 4 & 2 \\
5 & 1 & 5 & 2 & 5 & 1 \\
& & 6 & 1 & 6 & 1
\end{tabular}

Note: This table gives an overview of the structure of missing inputs and the total number of inconsistent decisions in each condition (without time pressure and under time pressure) together with their respective absolute frequencies. 
In a next step, we present descriptive analyses for the sub-samples of 91 subjects with no missing input, of 53 subjects with at least one missing input, as well as for 62 subjects without any missing input and inconsistency, and 82 subjects with at least one missing input and / or inconsistency. These results serve as a robustness check for the findings obtained by the analysis of all 144 subjects.

Figure 6 illustrates the descriptive analysis with respect to present-bias for 91 subjects with no missing input. Similar to the whole sample of 144 subjects, we find very limited evidence for present-bias. All $p$-values are obtained by applying Wilcoxon signed-rank tests. For the time pressure as well as the no time pressure condition, we find mean fractions of the budget allocated to the earlier date being marginally higher for nFED than for FED decisions. The opposite (mean FED allocations are higher than mean nFED decisions) is true for all price ratios except for 1.05 and 2.22 in the long delay condition without time pressure, whereas under time pressure this is true for all price ratios except for 1.05, 1.18, and 1.67. Without time pressure, neither differences in the short delay nor in the long delay condition are significant $(p>0.1383)$. Under time pressure, differences are significant for price ratios of 1.43 and 1.82 on the $5 \%$-level. For long delay, the only significant difference is at $P=1.00(p=0.0900)$. Taken together, we do not find evidence for present-bias across conditions, which supports the results of our main analysis of the whole sample of 144 subjects.

Similarly, Figure 7 illustrates the descriptive analysis with respect to present-bias for 53 subjects with at least one missing input and are thus those who are most influenced by time pressure. Again, we find very limited evidence for present-bias across conditions, obtaining $p$-values by applying Wilcoxon signed-rank tests. For the time pressure as well as the no time pressure condition, we find mean fractions of the budget allocated to the earlier date being marginally higher for nFED than for FED decisions, whereas for long delay the mean fraction allocated to the earlier date is higher for FED decisions for all price ratios except for $P=2.22$ without time pressure, and $P=1.05$ as well as $P=2.22$ under time pressure. Since subjects with inconsistent choices are also included in this sub-sample, we find curves for mean allocated shares of the budget to the earlier date not monotonically decreasing in the price ratio for the condition under time pressure, but increasing at a price ratio of 1.25 with a subsequent decrease for both $\mathrm{nFED}$ and FED decisions. Since our regressions can account for these non-monotonic decisions, we decided to leave them in our sample. Without time pressure, differences in mean allocated shares for nFED and FED decisions are only marginally significant at price ratios of $P=1.11,1.25(5 \%$-level $)$ and $2.22(10 \%$-level). For long delay, all differences except for $P=2.22(p=0.0254)$ are not significant $(p>0.1915)$. Under time pressure, results are again similar. For short delay, differences are 

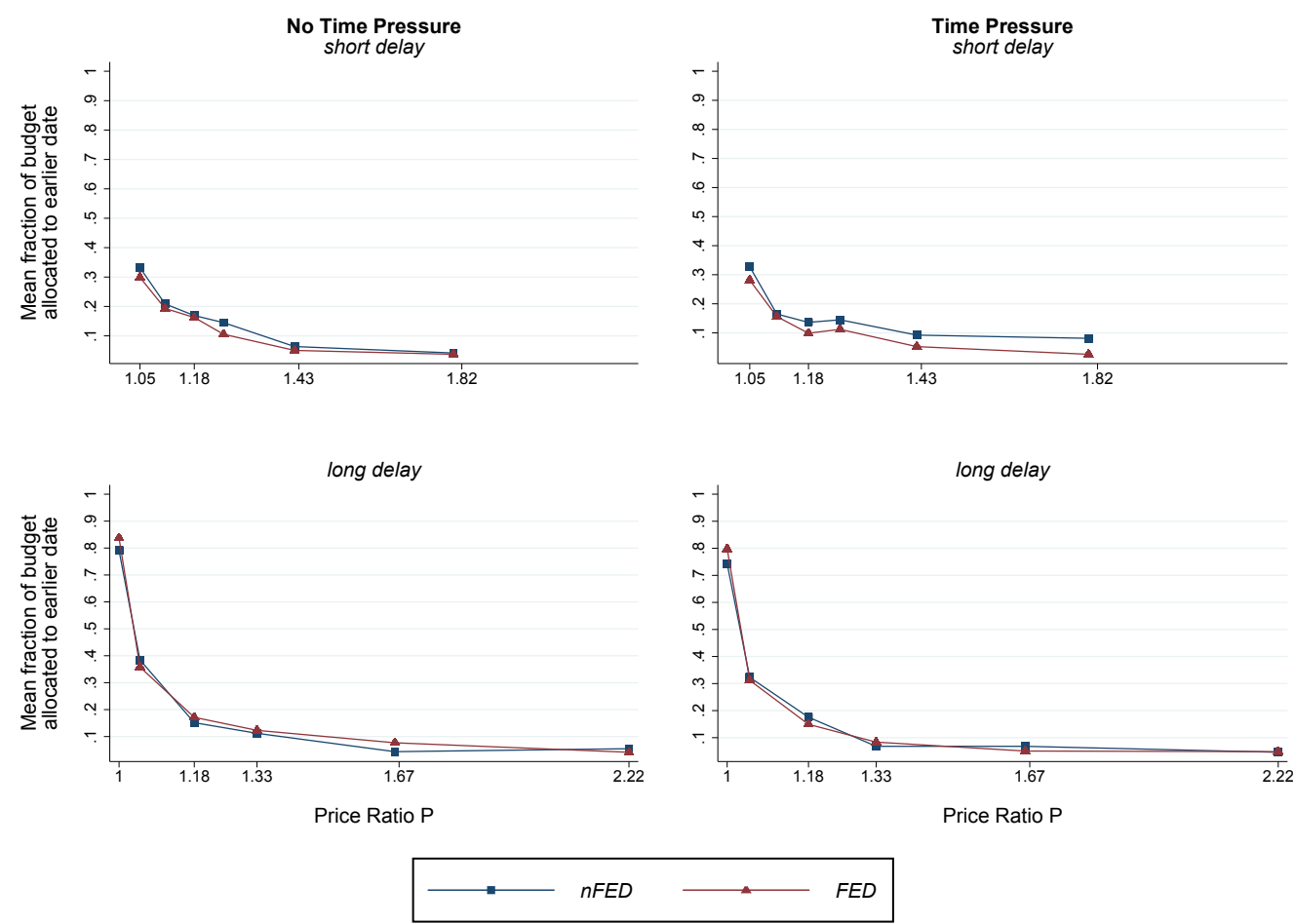

Note: The top row of the figure compares the mean allocated share of the budget to the earlier date between $\mathrm{nFED}$ and FED decisions for a time delay of 35 days, whereas the bottom row shows differences for a delay length of 63 days.

Figure 6: Comparison of present-bias with and without time pressure: 91 subjects with no missing input

significant for price ratios of $1.11(p=0.0030), 1.18(p=0.0083), 1.43(p=0.0044)$; all other differences are not significant with $p>0.2154$. For long delay, all differences are insignificant with $p>0.3224$ except for $P=1.33(p=0.0403)$. Taken together, we also do not find evidence for present-bias across conditions for the sub-sample of subject which are most affected by time pressure.

To be able to distinguish whether differences in effects across specifications in different sub-samples are due to inconsistent choices or due to missing input, we present the descriptive analysis of present-bias in Figure 8 for the sub-sample of 62 subjects with no inconsistencies and no missing input. We find similar patterns as in the whole sample with 144 subjects as well as for all other sub-samples previously summarized, obtaining $p$-values again by applying Wilcoxon signed-rank tests. For no time pressure, in the short delay conditions mean allocated shares to the earlier date are marginally higher for $\mathrm{nFED}$ decisions compared to FED decisions for price ratios of 1.43 and 1.82, where mean allocations are marginally higher for FED decisions. In the long delay condition, mean allocations to the earlier date are higher for FED decisions for all price ratios except for $P=1.05$ and $P=1.18$. However, differences are only significant for price ratios of 

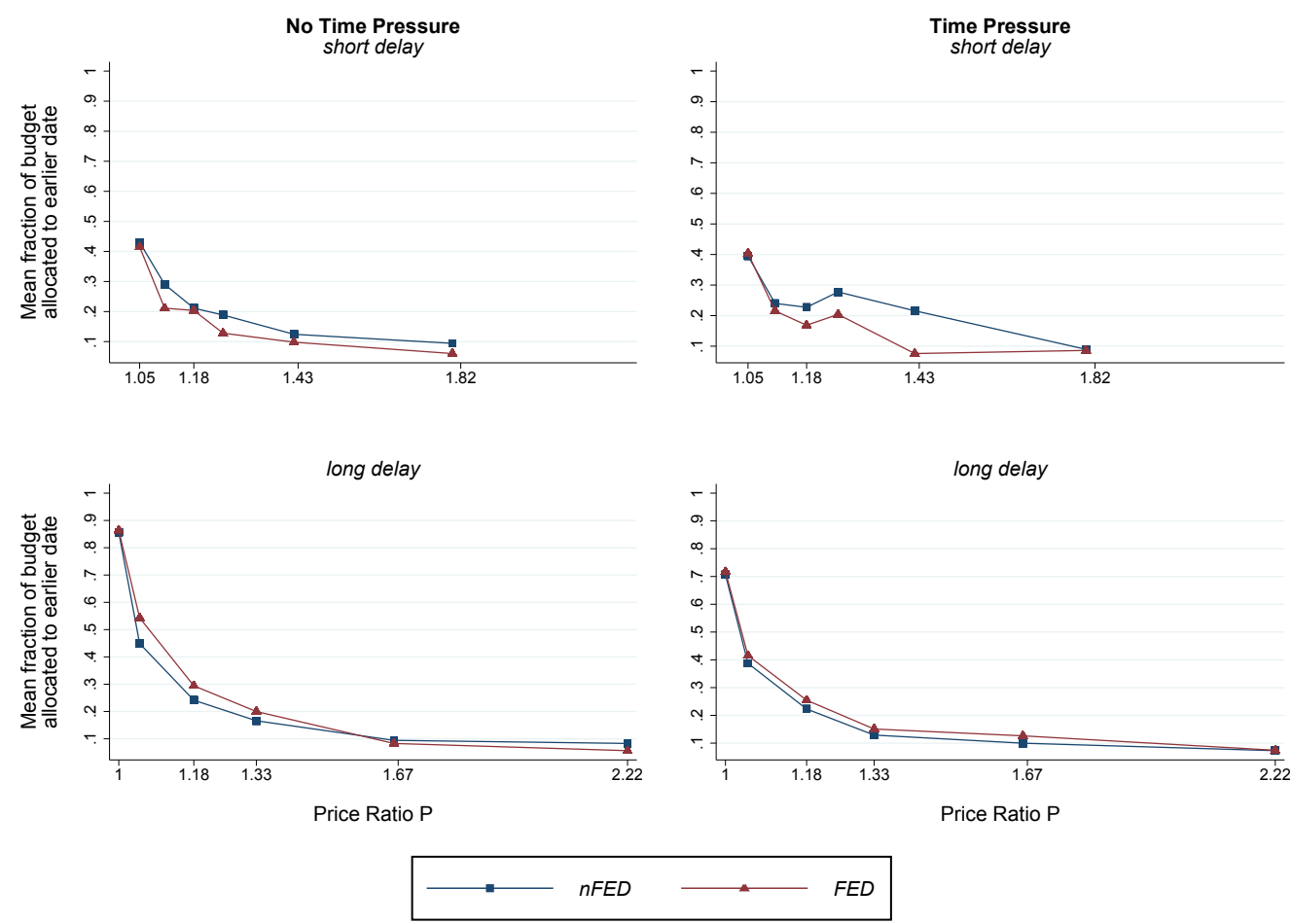

Note: The top row of the figure compares the mean allocated share of the budget to the earlier date between $\mathrm{nFED}$ and FED decisions for a time delay of 35 days, whereas the bottom row shows differences for a delay length of 63 days.

Figure 7: Comparison of present-bias with and without time pressure: 53 subjects with at least one missing input

$1.11(p=0.0606), 1.18(p=0.0833)$, and $1.25(p=0.0833)$ for the short delay condition; all other differences are not significant $(p>0.3173)$. For long delay, differences are significant for $P=1.05$ ( $p=0.0350)$ and $P=1.18(p=0.0833)$, all other $p$-values $>0.1573$. Under time pressure, all differences for both short and long delay conditions are insignificant with $p>0.1573$ except for $p=1.00$ in the long delay condition, where the difference is significant on the $5 \%$-level. We thus do not find overall evidence for present-bias across conditions, supporting previous findings obtained from the whole sample and all other sub-samples.

\section{A.3 Robustness Checks for NLS and ICT specifications}

Table 5 displays aggregate estimates for NLS and ICT regressions for all subjects with no missing input and no inconsistencies (62 subjects), and regressions for the sub-sample of subjects with at least one missing input and / or one inconsistent choice (82 subjects) as robustness checks for the results presented in the main analysis in Section 5.2. Again, results mainly go in the same direction as for estimates presented in the main part. All $p$-values presented are obtained by applying Wald tests. We can reject linear utility at the $1 \%$-level across all specifications and 

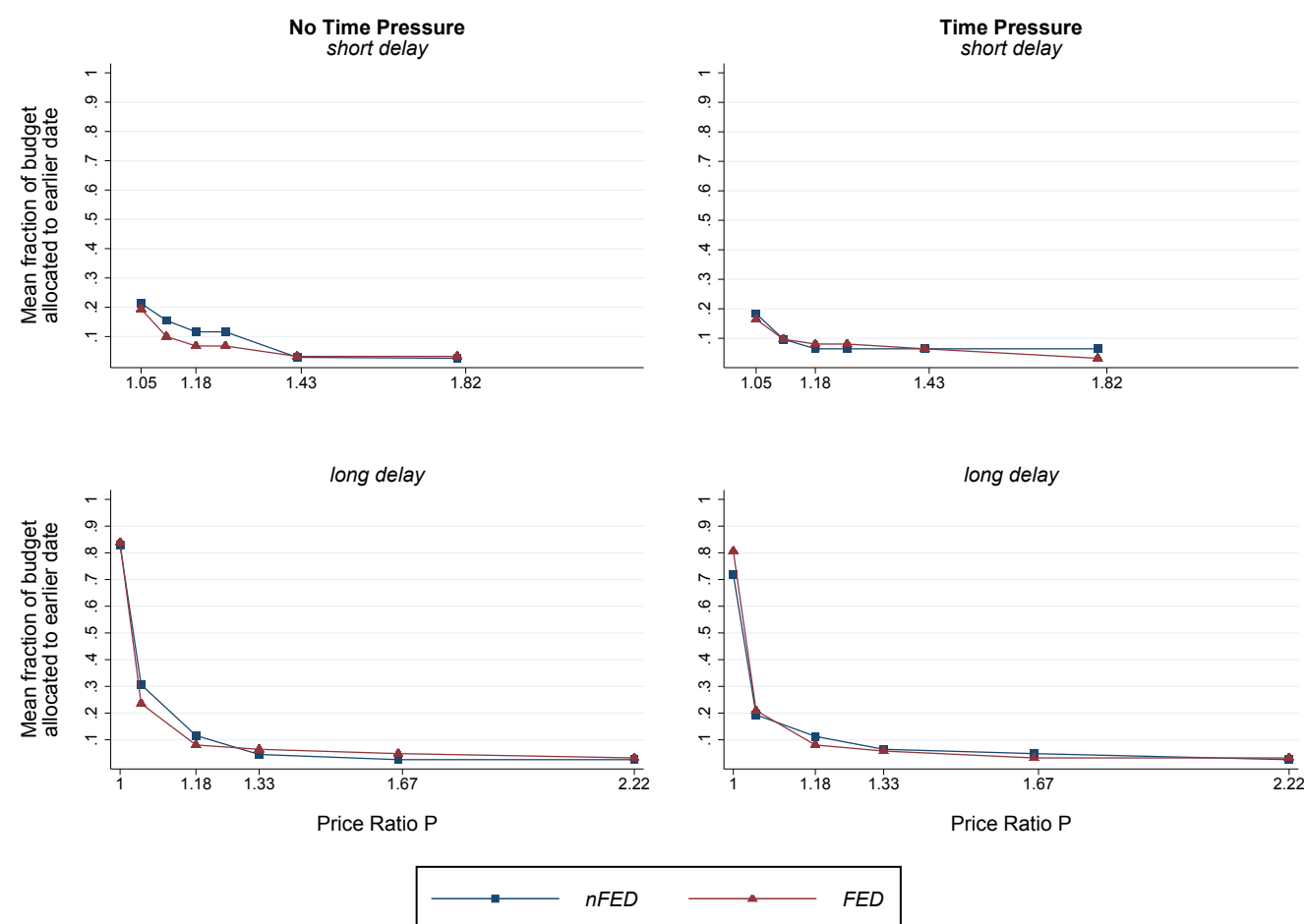

Note: The top row of the figure compares the mean allocated share of the budget to the earlier date between $\mathrm{nFED}$ and FED decisions for a time delay of 35 days, whereas the bottom row shows differences for a delay length of 63 days.

Figure 8: Comparison of present-bias with and without time pressure: 62 subjects with no missing input and no inconsistencies

conditions. For the sub-sample of 62 subjects with no missing input and no inconsistent decision in each condition, we find a marginally significant present-bias on the aggregate, with $\beta$ being significantly different from 1 with $p=0.0922$ for NLS regressions. Comparing $\beta$ across conditions, we find that parameters for present-bias are significantly different across conditions $(p=0.0257)$. Differences for utility function curvature and discounting are not significant with $p=0.9541$ and $p=0.4513$, respectively. Taken together, for this sub-sample preferences are also stable across conditions. Additionally, ICT regressions confirm directional findings.

Finally, we compare previous results with estimates for the sub-sample of 82 subjects with at least one missing input and / or one inconsistency in at least one of the conditions. We again find utility being significantly different from linearity at the 1\%-level across conditions and specifications. For both conditions, we cannot reject exponential discounting ( $p=0.1833$ without time pressure, $p=0.4265$ under time pressure), parameters are only marginally significantly different across conditions $(p=0.0743)$. We find the discounting parameter $\delta$ being significantly different across conditions with $p=0.0266$. 
Taken together, we find our results obtained from the whole sample with 144 subjects being robust to various specifications when analyzing different sub-samples. 
Table 5: Aggregate Parameter Estimates

\begin{tabular}{|c|c|c|c|c|c|c|c|c|}
\hline & \multicolumn{4}{|c|}{62 Subjects (no missings and no inconsistencies) } & \multicolumn{4}{|c|}{82 Subjects (missings and/or inconsistencies) } \\
\hline & \multicolumn{2}{|c|}{$\begin{array}{c}\text { No Time Pressure } \\
(\mathrm{NLS})\end{array}$} & \multicolumn{2}{|c|}{$\begin{array}{l}\text { Time Pressure } \\
\begin{array}{ll}(\mathrm{NLS}) & (\mathrm{ICT})\end{array}\end{array}$} & \multicolumn{2}{|c|}{$\begin{array}{l}\text { No Time Pressure } \\
\text { (NLS) } \quad \text { (ICT) }\end{array}$} & \multicolumn{2}{|c|}{$\begin{array}{l}\text { Time Pressure } \\
(\mathrm{NLS})\end{array}$} \\
\hline$\alpha$ & $\begin{array}{c}0.9757^{* * *} \\
(0.0033)\end{array}$ & $\begin{array}{c}0.9978^{* *} \\
(0.0011)\end{array}$ & $\begin{array}{c}0.9759^{* * *} \\
(0.0034)\end{array}$ & $\begin{array}{c}0.9991^{* *} \\
(0.0005)\end{array}$ & $\begin{array}{c}0.9163^{* * *} \\
(0.0095)\end{array}$ & $\begin{array}{c}0.9821 * * * \\
(0.0042)\end{array}$ & $\begin{array}{c}0.9102^{* * * *} \\
(0.0097)\end{array}$ & $\begin{array}{c}0.9734^{* * *} \\
(0.0065)\end{array}$ \\
\hline$\beta$ & $\begin{array}{l}0.9948^{*} \\
(0.0030)\end{array}$ & $\begin{array}{l}1.0032 \\
(0.0138)\end{array}$ & $\begin{array}{l}1.0039 \\
(0.0040)\end{array}$ & $\begin{array}{l}1.0352^{*} \\
(0.0180)\end{array}$ & $\begin{array}{l}1.0120 \\
(0.0089)\end{array}$ & $\begin{array}{l}1.0149 \\
(0.0156)\end{array}$ & $\begin{array}{c}0.9905 \\
(0.0119)\end{array}$ & $\begin{array}{c}0.9661 \\
(0.0237)\end{array}$ \\
\hline$\delta$ & $\begin{array}{c}0.9995 * * * \\
(.0001)\end{array}$ & $\begin{array}{c}0.9999 \\
(0.0003)\end{array}$ & $\begin{array}{l}0.9996^{* * *} \\
(.0001)\end{array}$ & $\begin{array}{l}1.0004 \\
(0.0005)\end{array}$ & $\begin{array}{c}0.9986^{* * *} \\
(0.0002)\end{array}$ & $\begin{array}{c}0.9980^{* * *} \\
(0.0004)\end{array}$ & $\begin{array}{c}0.9991^{* * *} \\
(0.0002)\end{array}$ & $\begin{array}{l}0.9991^{*} \\
(0.0005)\end{array}$ \\
\hline$\tau$ & $\begin{array}{l}- \\
-\end{array}$ & $\begin{array}{c}47.8974 \\
(20.5454)\end{array}$ & $\begin{array}{l}- \\
-\end{array}$ & $\begin{array}{l}7.9009 \\
(1.3014)\end{array}$ & $\begin{array}{l}- \\
-\end{array}$ & $\begin{array}{c}9.9077 \\
(1.7318)\end{array}$ & $\begin{array}{l}- \\
-\end{array}$ & $\begin{array}{l}7.9012 \\
(1.3015)\end{array}$ \\
\hline rate & 0.2001 & 0.0412 & 0.1723 & -0.1615 & 0.6653 & 1.0575 & 0.3655 & 0.4476 \\
\hline $\begin{array}{l}\text { \# Observations } \\
\text { \# Clusters }\end{array}$ & $\begin{array}{c}1,488 \\
62\end{array}$ & $\begin{array}{c}1,488 \\
62\end{array}$ & $\begin{array}{c}1,488 \\
62\end{array}$ & $\begin{array}{c}1,488 \\
62\end{array}$ & $\begin{array}{c}1,968 \\
82\end{array}$ & $\begin{array}{c}1,968 \\
82\end{array}$ & $\begin{array}{c}1,879 \\
82\end{array}$ & $\begin{array}{c}1,879 \\
82\end{array}$ \\
\hline $\begin{array}{l}\text { Note: Para } \\
* * \text {, and } * \text { in } \\
\text { exponential } \\
\text { to identify u } \\
\text { rate, comput } \\
\text { combinations } \\
\text { Broyden-Flet }\end{array}$ & $\begin{array}{l}\left.\text { S } \frac{s}{\delta}\right) \\
\text { egression } \\
\text {-Goldfarb }\end{array}$ & $\begin{array}{l}\text { d via } ~ \\
\text { on the }\end{array}$ & $\begin{array}{l}\text { ICT reg } \\
0, \text { and } 1 \\
\text { dard disc } \\
\text { ly from t } \\
\text { are give } \\
\text { dard err } \\
\text { mization }\end{array}$ & $\begin{array}{l}\text { s; where IC } \\
\text { el, respecti } \\
\mathrm{g}(\delta=1) \text { o } \\
\text { hastic distu } \\
\text { arentheses a } \\
\text { computed } \\
\text { hm. }\end{array}$ & $\begin{array}{l}\text { ates results } \\
\mathrm{r} \text { testing th } \\
\text { ggregate le } \\
\text { term } \tau \text {. rat } \\
\text { stered on th } \\
\text { Delta meth }\end{array}$ & $\begin{array}{l}\text { obtained by } \\
\text { e hypothese } \\
\text { el (Wald te } \\
e \text { is the com } \\
\text { e individual } \\
\text { od. ICT re }\end{array}$ & $\begin{array}{l}\text { cifying Fechr } \\
\text { linear utilit } \\
\text { For ICT it } \\
\text { annual ind } \\
\text { Paramete } \\
\text { ons are estin }\end{array}$ & $\begin{array}{l}\text { errors. ***, } \\
\alpha=1) \text { and } \\
\text { not possible } \\
\text { lual discount } \\
\text { ire nonlinear } \\
\text { ed using the }\end{array}$ \\
\hline
\end{tabular}




\section{A.4 Individual Parameter Estimates}

Table 6 displays individual parameter estimates for 142 out of 144 subjects. For two subjects, it was not possible to estimate individual parameters; therefore they do not enter this overview. Standard deviations are higher for the time pressure condition for the curvature of the utility function as well as standard discounting and thus can be seen as an indicator for a higher level of heterogeneity. Medians for $\alpha$ and $\beta$ are equal across conditions, which is again evidence for stability on the individual level. Additionally, medians are close to the aggregate estimates presented in Section 5.2.

Table 6: Individual Parameter Estimates

\begin{tabular}{ccccccc}
\hline \hline Parameter & N & Median & Mean & $\begin{array}{c}\text { Standard } \\
\text { Deviation }\end{array}$ & $\begin{array}{c}\text { 10th } \\
\text { Percentile }\end{array}$ & $\begin{array}{c}90 \text { th } \\
\text { Percentile }\end{array}$ \\
\hline No Time Pressure & & & & & & \\
$\alpha$ & 142 & 0.9992 & -0.4718 & 11.1626 & 0.8913 & 0.9996 \\
$\beta$ & 142 & 0.9961 & 0.9792 & 0.2457 & 0.8841 & 1.112 \\
$\delta$ & 142 & 0.9993 & 0.9928 & 0.0537 & 0.9935 & 0.9998
\end{tabular}

Time Pressure

$\begin{array}{lllcccc}\alpha & 142 & 0.9992 & -1.0185 & 15.1048 & 0.7972 & 0.9995 \\ \beta & 142 & 0.9961 & 1237360 & 1.47 e^{0} 7 & 0.7467 & 1.1504 \\ \delta & 142 & 0.9996 & 0.9853 & 0.1185 & 0.9944 & 1.0011\end{array}$

Note: All estimates are obtained using NLS. For two subjects, it was not possible to estimate individual parameters, therefore they do not enter this summary statistic.

Table 7 gives an overview of differences in parameters on the individual level. For each parameter of interest, the table indicates whether the estimated parameter on the individual level in the time pressure condition was below or above the parameter in the condition without time pressure. Additionally, we test whether the differences are significant; stability is rejected for all $p$-values below the $10 \%$-level.

For 36 subjects $(25.35 \%)$, all parameters are identical across both conditions. In 78 cases, parameters for the curvature of the utility function $\alpha$ under time pressure are slightly below (44 subjects) or above (34 subjects) the condition without time pressure; differences are not significant and stability cannot be rejected. In total, for $80.28 \%$ of all subjects, $\alpha$ remained stable across conditions. Only for 28 subjects, stability can be rejected at least at the 10\%-level. For 
present-bias $\beta$, results are quite similar. In 84 cases parameters are not significantly different from the no time pressure condition (below for 36 subjects, above for 48 subjects). In total $84.51 \%$ of all subjects exhibit a stable degree of present-bias, whereas for 22 out of 142 subjects stability can be rejected. Considering standard discounting $\delta$, for a fraction of $66.90 \%$ of all subjects stability cannot be rejected (for 24 subjects, parameters under time pressure are below the estimates without time pressure, for 35 subjects the opposite is true), for 47 subjects stability can be rejected at least at the $10 \%$-level. 
Table 7: Stability of individual parameter estimates

\begin{tabular}{|c|c|c|c|c|c|c|}
\hline & \multicolumn{2}{|c|}{$\alpha$} & \multicolumn{2}{|c|}{$\beta$} & \multicolumn{2}{|c|}{$\delta$} \\
\hline & $\begin{array}{c}\text { Stability } \\
\text { not rejected }\end{array}$ & $\begin{array}{l}\text { Stability } \\
\text { rejected }\end{array}$ & $\begin{array}{c}\text { Stability } \\
\text { not rejected }\end{array}$ & $\begin{array}{l}\text { Stability } \\
\text { rejected }\end{array}$ & $\begin{array}{c}\text { Stability } \\
\text { not rejected }\end{array}$ & $\begin{array}{l}\text { Stability } \\
\text { rejected }\end{array}$ \\
\hline $\mathrm{TP}<\mathrm{NTP}$ & $\begin{array}{c}44 \\
(30.99 \%)\end{array}$ & $\begin{array}{c}18 \\
(12.68 \%)\end{array}$ & $\begin{array}{c}36 \\
(25.35 \%)\end{array}$ & $\begin{array}{c}16 \\
(11.27 \%)\end{array}$ & $\begin{array}{c}24 \\
(16.90 \%)\end{array}$ & $\begin{array}{c}21 \\
(14.79 \%)\end{array}$ \\
\hline $\mathrm{TP}=\mathrm{NTP}$ & $\begin{array}{c}36 \\
(25.35 \%)\end{array}$ & - & $\begin{array}{c}36 \\
(25.35 \%)\end{array}$ & - & $\begin{array}{c}36 \\
(25.35 \%)\end{array}$ & - \\
\hline $\mathrm{TP}>\mathrm{NTP}$ & $\begin{array}{c}34 \\
(23.94 \%)\end{array}$ & $\begin{array}{c}10 \\
(7.04 \%)\end{array}$ & $\begin{array}{c}48 \\
(33.80 \%)\end{array}$ & $\begin{array}{c}6 \\
(4.23 \%)\end{array}$ & $\begin{array}{c}35 \\
(24.65 \%)\end{array}$ & $\begin{array}{c}26 \\
(18.31 \%)\end{array}$ \\
\hline Total & $\begin{array}{c}114 \\
(80.28 \%)\end{array}$ & $\begin{array}{c}28 \\
(19.72 \%)\end{array}$ & $\begin{array}{c}120 \\
(84.51 \%)\end{array}$ & $\begin{array}{c}22 \\
(15.49 \%)\end{array}$ & $\begin{array}{c}95 \\
(66.90 \%)\end{array}$ & $\begin{array}{c}47 \\
(33.10 \%)\end{array}$ \\
\hline
\end{tabular}

Note: For each parameter of interest, the table indicates whether the estimated parameter on the individual level in the time pressure condition (TP) Note: For each parameter of interest, the table indicates whether the estimated parameter on the individual level in the time pressure condition (TP)
was below, equal, or above the parameter in the condition without time pressure (NTP). Stability is rejected for all p-values below the $10 \%$-level (Wald
tests). 


\section{B Instructions}

Instructions are translated from German. Differences in the two order conditions (no time pressure followed by time pressure vs. time pressure followed by no time pressure) are given in parentheses.

The second part of the experiment consists of $\mathbf{4 8}$ decisions. In each of these 48 decisions you have to decide on how to allocate your budget between two points in time, one time is earlier and one is later. Both the earlier and the later point in time will vary across decisions.

Each of the subsequent 48 decisions will be presented to you on a single screen. All these decisions consist of six options. Each option consists of an earlier payment AND a later payment. You are asked to choose your preferred option by clicking the button below the respective option. In each decision you can only chose one of the six options. Please note that later payments increase when earlier payments decrease.

\section{Example}

In this example you are asked to choose your preferred combination of a payment in $\boldsymbol{X}$ Weeks $\boldsymbol{A N D}$ a payment in $\boldsymbol{Y}$ Weeks. The value of the earlier payment varies between $\boldsymbol{A}$ Euro and $\boldsymbol{O}$ Euro, whereas the value of the later payment varies between $\boldsymbol{O}$ Euro and B Euro. This decision problem would be presented on screen as follows:

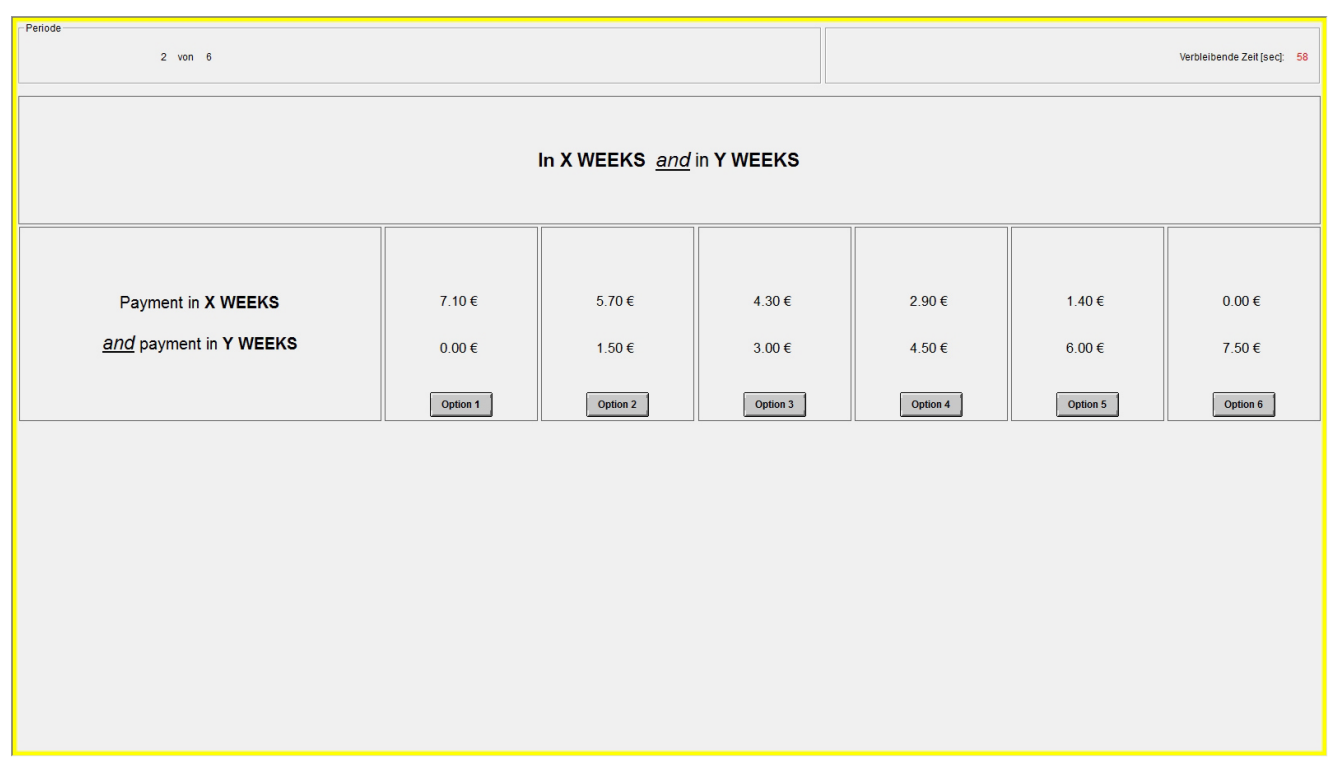


You will be making 48 such decisions in total. Each decision is displayed on a separate screen. For decisions 1 to 24 you have a maximum of $\mathbf{6 0}$ seconds [only $\mathbf{5}$ seconds] to decide on the option of your choice; for decisions 25 to 48 you have only $\mathbf{5}$ seconds $[\mathbf{6 0}$ seconds] to make your decisions. In the upper left part of the screen the number of the current decision situation is displayed to inform you in which of the 48 decision situations you currently are.

\section{Your payment in this part is determined as follows}

At the end one of the 48 decision situations is chosen randomly; your chosen option in this decision situation is then actually paid out. You will only be informed about the randomly chosen decision situation at the end of the experiment. Since you do not know which of the 48 decisions is chosen, it is optimal to decide as if each single decision is relevant for payment. You do not have to make use of the whole decision time, however, in case you exceed the given time limit you will receive a payment of 0 Euro for this part.

\section{Important}

All payments from this part of the experiment will be transferred to your specified bank account. This applies to both the payments you receive today as well as the payments at a later point in time. The exact dates of the bank transfer are determined by the option you chose in the decision situation which was randomly chosen for payment by the computer. This will be displayed to you at the end of the experiment in detail.

\section{Questions}

In case you have any questions please raise your hand now. The experimenter will come to you and answer your questions privately. 
University of Innsbruck - Working Papers in Economics and Statistics Recent Papers can be accessed on the following webpage:

http://eeecon.uibk.ac.at/wopec/

2016-24 Florian Lindner, Julia Rose: No need for more time: Intertemporal allocation decisions under time pressure

2016-23 Christoph Eder, Martin Halla: The long-lasting shadow of the allied occupation of Austria on its spatial equilibrium

2016-22 Christoph Eder: Missing men: World War II casualties and structural change

2016-21 Reto Stauffer, Jakob Messner, Georg J. Mayr, Nikolaus Umlauf, Achim Zeileis: Ensemble post-processing of daily precipitation sums over complex terrain using censored high-resolution standardized anomalies

2016-20 Christina Bannier, Eberhard Feess, Natalie Packham, Markus Walzl: Incentive schemes, private information and the double-edged role of competition for agents

2016-19 Martin Geiger, Richard Hule: Correlation and coordination risk

2016-18 Yola Engler, Rudolf Kerschbamer, Lionel Page: Why did he do that? Using counterfactuals to study the effect of intentions in extensive form games

2016-17 Yola Engler, Rudolf Kerschbamer, Lionel Page: Guilt-averse or reciprocal? Looking at behavioural motivations in the trust game

2016-16 Esther Blanco, Tobias Haller, James M. Walker: Provision of public goods: Unconditional and conditional donations from outsiders

2016-15 Achim Zeileis, Christoph Leitner, Kurt Hornik: Predictive bookmaker consensus model for the UEFA Euro 2016

2016-14 Martin Halla, Harald Mayr, Gerald J. Pruckner, Pilar García-Gómez: Cutting fertility? The effect of Cesarean deliveries on subsequent fertility and maternal labor supply

2016-13 Wolfgang Frimmel, Martin Halla, Rudolf Winter-Ebmer: How does parental divorce affect children's long-term outcomes?

2016-12 Michael Kirchler, Stefan Palan: Immaterial and monetary gifts in economic transactions. Evidence from the field

2016-11 Michel Philipp, Achim Zeileis, Carolin Strobl: A toolkit for stability assessment of tree-based learners 
2016-10 Loukas Balafoutas, Brent J. Davis, Matthias Sutter: Affirmative action or just discrimination? A study on the endogenous emergence of quotas forthcoming in Journal of Economic Behavior and Organization

2016-09 Loukas Balafoutas, Helena Fornwagner: The limits of guilt

2016-08 Markus Dabernig, Georg J. Mayr, Jakob W. Messner, Achim Zeileis: Spatial ensemble post-processing with standardized anomalies

2016-07 Reto Stauffer, Jakob W. Messner, Georg J. Mayr, Nikolaus Umlauf, Achim Zeileis: Spatio-temporal precipitation climatology over complex terrain using a censored additive regression model

2016-06 Michael Razen, Jürgen Huber, Michael Kirchler: Cash inflow and trading horizon in asset markets

2016-05 Ting Wang, Carolin Strobl, Achim Zeileis, Edgar C. Merkle: Scorebased tests of differential item functioning in the two-parameter model

2016-04 Jakob W. Messner, Georg J. Mayr, Achim Zeileis: Non-homogeneous boosting for predictor selection in ensemble post-processing

2016-03 Dietmar Fehr, Matthias Sutter: Gossip and the efficiency of interactions

2016-02 Michael Kirchler, Florian Lindner, Utz Weitzel: Rankings and risktaking in the finance industry

2016-01 Sibylle Puntscher, Janette Walde, Gottfried Tappeiner: Do methodical traps lead to wrong development strategies for welfare? A multilevel approach considering heterogeneity across industrialized and developing countries

2015-16 Niall Flynn, Christopher Kah, Rudolf Kerschbamer: Vickrey Auction vs BDM: Difference in bidding behaviour and the impact of other-regarding motives

2015-15 Christopher Kah, Markus Walzl: Stochastic stability in a learning dynamic with best response to noisy play

2015-14 Matthias Siller, Christoph Hauser, Janette Walde, Gottfried Tappeiner: Measuring regional innovation in one dimension: More lost than gained?

2015-13 Christoph Hauser, Gottfried Tappeiner, Janette Walde: The roots of regional trust

2015-12 Christoph Hauser: Effects of employee social capital on wage satisfaction, job satisfaction and organizational commitment

2015-11 Thomas Stöckl: Dishonest or professional behavior? Can we tell? A comment on: Cohn et al. 2014, Nature 516, 86-89, "Business culture and dishonesty in the banking industry" 
2015-10 Marjolein Fokkema, Niels Smits, Achim Zeileis, Torsten Hothorn, Henk Kelderman: Detecting treatment-subgroup interactions in clustered data with generalized linear mixed-effects model trees

2015-09 Martin Halla, Gerald Pruckner, Thomas Schober: The cost-effectiveness of developmental screenings: Evidence from a nationwide programme forthcoming in Journal of Health Economics

2015-08 Lorenz B. Fischer, Michael Pfaffermayr: The more the merrier? Migration and convergence among European regions

2015-07 Silvia Angerer, Daniela Glätzle-Rützler, Philipp Lergetporer, Matthias Sutter: Cooperation and discrimination within and across language borders: Evidence from children in a bilingual city forthcoming in European Economic Review

2015-06 Martin Geiger, Wolfgang Luhan, Johann Scharler: When do Fiscal Consolidations Lead to Consumption Booms? Lessons from a Laboratory Experiment forthcoming in Journal of Economic Dynamics and Control

2015-05 Alice Sanwald, Engelbert Theurl: Out-of-pocket payments in the Austrian healthcare system - a distributional analysis

2015-04 Rudolf Kerschbamer, Matthias Sutter, Uwe Dulleck: How social preferences shape incentives in (experimental) markets for credence goods forthcoming in Economic Journal

2015-03 Kenneth Harttgen, Stefan Lang, Judith Santer: Multilevel modelling of child mortality in Africa

2015-02 Helene Roth, Stefan Lang, Helga Wagner: Random intercept selection in structured additive regression models

2015-01 Alice Sanwald, Engelbert Theurl: Out-of-pocket expenditures for pharmaceuticals: Lessons from the Austrian household budget survey 


\title{
University of Innsbruck
}

\section{Working Papers in Economics and Statistics}

2016-24

Florian Lindner, Julia Rose

No need for more time: Intertemporal allocation decisions under time pressure

\begin{abstract}
Time preferences drive decisions in many economic situations, such as investment contexts or salary negotiations. These situations are characterized by a very short time frame for decision making. Preferences are potentially susceptible to the confounding effects of time pressure, as proposed by dual-systems theory (Evans, 2006; Kahneman and Frederick, 2002). Results of standard methods of time preference elicitation can therefore not be directly mapped to environments characterized by severe time pressure since the underlying assumption of these models is that preferences are stable. To address the stability of time preferences under time pressure, we conduct a laboratory study with 144 subjects using convex time budgets (Andreoni and Sprenger, 2012) in order to elicit time preferences with and without time pressure in a within-subject design. We find lower present-bias under time pressure compared to the condition without time pressure on the aggregate, whereas utility function curvature and long-run discounting are stable across conditions. The findings are confirmed on the individual level. Embedding our results in dual-systems theory, how information is presented can serve as a potential means to exogenously decrease present-bias under time pressure.
\end{abstract}

ISSN 1993-4378 (Print)

ISSN 1993-6885 (Online) 